\title{
Review of the energy and economic parameters involved in the effectiveness of grid-connected PV systems installed in multi-storey buildings
}

\author{
Aldo Orioli*, Alessandra Di Gangi \\ D.D.E. Dipartimento dell'Energia, Università degli Studi di Palermo, Viale delle Scienze Edificio 9, 90128 Palermo, Italy
}

\section{H I G H L I G H T S}

- Photovoltaic penetration in urban areas was evaluated.

- The impact of the deviation of energy and economic parameters was analysed.

- The electricity demand coverage was estimated by means of gross energy cover factor.

- The level of the economic convenience PV systems was estimated by means of NPV/PVC.

\section{A R T I C L E I N F O}

\section{Article history:}

Received 6 March 2013

Received in revised form 30 July 2013

Accepted 5 August 2013

\section{Keywords:}

Photovoltaic

Grid-connected PV systems

Energy parameters

Economic parameters

\begin{abstract}
A B S T R A C T
The assessment of PV energy in an urban context is extremely complex because many factors have to be considered. Moreover, when the purpose is calculating the realistic amount of the electricity demand of a city that can be covered by the photovoltaic generation, it is necessary to estimate the number of photovoltaic systems whose installation is economically advantageous. Such a topic requires an economic analysis, which is affected by the number of energy and economic parameters involved and the values assigned to them to perform calculations. Some parameters are perfectly known and unvarying, like the paid incentives. Adversely, some parameters, like the efficiency degradation of photovoltaic panels, can only be supposed. Other parameters require some information that is specifically related to each particular photovoltaic system.

With the aim of estimating the influence of the manifold energy and economic parameters that characterize how photovoltaic penetration develops in urban areas, a specific study was conducted for a city in the south of Italy. A sensitivity analysis was carried out in order to verify parameters have an irrelevant influence and what are the parameters whose definition can be a crucial element of the energy and economic analysis of photovoltaic systems because dramatically impact on the results.

The presented study represents a valuable help for photovoltaic systems designers and energy decision-makers because it permits to evaluate the impact of the deviations of the main parameters on the profitability of photovoltaic systems and the role played by them in the effectiveness of the energy policies implemented to achieve the required shares of electricity demand coverage.
\end{abstract}

(c) 2013 Elsevier Ltd. All rights reserved.

\section{Introduction}

To fulfil the energy targets, which were decreed by the European Union (EU) with the Directive 2009/28/EC, the renewable energy sources (RES) have to assure both the adequate electricity generation and the economic convenience of the investment. These two concurring requirements always play a crucial role in the rapid penetration of any new energy technology. Actually, even though the electrical requirements are fully covered by a photovoltaic (PV) system, it is reasonable to presume that the returns may be

\footnotetext{
* Corresponding author. Tel.: +39 09123861905; fax: +39 091484425.

E-mail addresses: orioli@dream.unipa.it, aldo.orioli@unipa.it (A. Orioli).
}

not sufficient to offset the initial costs and the disbursements over the years. Energy and economic aspects are yet more decisive elements when multi-storey buildings, which are peculiar to the urban areas, are considered. Because the roof surface of a building have to be used in equal portions by each co-homeowner, when the number of floors increases, the electricity generated by each PV system may result lower than the household electrical demand. Nevertheless, even PV systems that not satisfy the full energy demand of the flat may be economically convenient as long as the costs for installation and operation are offset by the incentives and the reduction in the electricity bills. Unfortunately, the ratio of the generated PV electricity to the global cost of the facility varies with the size of the PV system and for this reason assessing the 


\section{Nomenclature}

$C_{P V} \quad$ gross energy cover factor of the district (\%)

$C_{t} \quad$ cash flow at the generic $t$-th year $(€)$

$C_{0} \quad$ initial investment cost $(€)$

$D_{\text {Day }} \quad$ yearly day electricity demand $(\mathrm{kW} \mathrm{h})$

$D_{j} \quad$ yearly electricity demand of the generic $j$-th PV system $(\mathrm{kWh})$

$D_{\text {Night }} \quad$ yearly night electricity demand ( $\mathrm{kW} \mathrm{h}$ )

$D_{\text {Total }} \quad$ yearly electricity demand of the district $(\mathrm{kW} \mathrm{h})$
$E_{P V, j} \quad$ yearly electricity generated by the generic $j$-th PV system $(\mathrm{kW} \mathrm{h})$

$E_{P V T o t a l}$ yearly electricity produced by all PV systems $(\mathrm{kW} \mathrm{h})$

$i \quad$ weighted average cost of capital (\%)

IRR internal rate of return (\%)

$N_{P V} \quad$ number of PV systems

NPV net present value $(€)$

$N_{y} \quad$ life time of the investment (years) actual economic viability becomes a condition necessary for the success the project.

The assessment of PV energy in an urban context is extremely complex because the factors that interact are manifold and hard to be contextually analysed. Hofierka and Kaňuk [1] assessed the photovoltaic potential in Bardejov, Slovakia, and Vardimon [2] analysed five Israeli cities (Jerusalem, Tel Aviv, Haifa, Beersheba, Eilat). Ordóñez et al. [3] studied the solar energy capacity in Andalusia, Spain, Izquierdo et al. [4] focused on roof surfaces of all autonomous Regions of Spain, and Wiginton et al. [5] and Nguyen et al. [6] quantified rooftop solar photovoltaic potential of a region of south eastern Ontario, Canada. Viana et al. [7] assessed the potential of concentrating solar photovoltaic generation in Brazil, and Šúri et al. [8] analysed the potential of solar electricity generation in the European Union states. Pelland and Poissant [9] evaluated the potential of building integrated photovoltaics (BIPV) in Canada. Kaan and Reijenga [10] presented many examples of PV systems in order to demonstrate that BIPVs can be aesthetically neutral or visually attractive elements in architecture. Hachem et al. [11] showed that a variety of housing unit shapes, densities and site layouts can be accommodated in ways that compensate for increased energy consumption by increased generation, as well as by spread of peak generation timing. Strzalka et al. [12] investigated on large scale integration of photovoltaics in a residential district near Stuttgart, Germany.

Many different techniques were used to estimate the roof collecting surfaces. In several studies on building-integrated solar energy applications the amount of available area was assumed as an input data. For city areas, vectorial GIS orthomaps $[1,2,4]$, and urban maps obtained from Google Earth ${ }^{\mathrm{TM}}$ [3] were used to create polygon objects representing the building roofs. The estimation of region areas was performed using the machine leaner functions and classification algorithms of Feature Analyst, which is an advanced feature extraction program existing as an extension of ArcGIS [5], and the open source Geographical Resource Analysis System (GRASS) [6]. For continent and subcontinent areas CORINE Land Cover and GIS databases were also used [7,8].

Even the conversion efficiency of PV systems, which mainly depends on the solar irradiation, the silicon slab operating temperature, the spectral response and the electrical load has a significant role in the order of the energy assessments. When the energy assessments is based on mean constant value of the conversion efficiency, economical predictions are too optimistic ant they can lead to the installation of PV systems that disappoint all investor expectations. With the exception of some researchers $[1,2]$, who evaluated the power of the PV system using the current-voltage characteristics of the used PV panels, the conversion efficiency was often assumed constant or, at most, only changing with the silicon temperature.

The economic aspect related to the feasibility of PV systems requires an accurate analysis based on the evaluation of all costs and benefits. The deviation of each crucial factor involved in the study
- PV system costs, selling and purchasing power prices, discount rate, degradation rate in the efficiency of the PV panels, replacement of the PV panels and inverter, maintenance costs, assurance costs, inflation, incentives, shading factor - biases the convenience and prospective profit that can derive from investing in sustainable technologies. Van der Zwaan and Rabl [13] stated that, mainly due to its high costs, PV electricity was unlikely to pay a major role in global energy supply and carbon emission abatement before 2020 . Hongbo et al. [14] performed the economic optimisation and sensitivity analysis of PV systems in residential buildings in Japan. Li et al. [15] examined the economic viability domestic PV systems in Ireland. Martinez-Cesena et al. [16] proposed the assessment of the economic convenience of defer investments in PV systems with the expectation that better PV panels will become available in the future. A techno-economic analysis of wind-solar hybrid renewable energy system for urban high-rise application was presented by Chong et al. [17].

In the last years Italy and other countries, like Spain and Germany, have heavily reduced the incentives to support PV installations. The shift from the initial generous values, which is connected to the predicted drop in the PV devices price, does not ensure that FIT payments will be able to adequately recover the investment and management costs. The PV policies in Germany, Spain and Greece were analysed by Lüthi [18]. Poullikkas [19] observed that the economic feasibility of large PV parks in Cyprus, in absence of appropriate FIT, has a critical value. Celik [20] claimed the need of economic subsidies in order to propagate the alternative energy systems. Celik et al. [21] analysed the energy statistics of 15 European Union countries and inferred that subsides and incentives are vital in promoting solar thermal and PV collectors. Zahedi [22] performed an economical model to determine the accurate FIT in all states of Australia. Rigter [23] calculated what the level of tariffs would have to be in China. Danchev et al. [24] showed that the rate of FIT de-escalation does not guarantee return rate over the time in Greece. Papadopoulos and Karteris [25] discussed a quantitative assessment of the FIT introduced in Greece. Campoccia et al. [26] compared the supporting measures adopted by France, Germany, Italy and Spain. Dusonchet and Telaretti $[27,28]$ extended the comparison to 17 western and 10 eastern European Union countries. Sivaraman and Horne [29] examined the Australian policy to increase small scale grid-connected PV deployment. Dinçer [30] analysed the PV electricity status, potential ad policies of Spain, Germany, United States of America, Japan and China.

To correctly assess the viability of the investment, it is also important to examine the impact of the load mismatch. Myers et al. [31] assumed that the investment in solar PV in Wisconsin approached a practical limit due to available solar radiation and mismatch between demand and electrical generation. Widén et al. [32] presented a methodology for evaluation of options for improved load matching. Paatero and Paatero [33] analysed for Lisbon and Helsinki climates the effects of a high level of photovoltaics connected in the middle voltage distribution network. Denholm 
and Margolis [34] considered the constraint of traditional electricity generation plants to reduce output and accept PV generated energy. Stodola and Modi [35] faced the problem of evaluating the maximum deployment that would permit $95 \%$ of the annual output from PV to be utilised without reducing the output of the baseload plants located in 32 regions of USA.

In this paper the authors deal with the subject by analysing all energy and economic aspects at the same time. In order to reach concrete conclusions the analysis focused on a district of a southern Italian city. The influence of all parameters was studied in order to assess the importance of each of them in modifying the results of the energy and economic analysis of PV systems. The effects of the parameters were discussed in relation to the minimum electricity demand coverage $(17 \%)$ that is the target set by Directive 2009/28/EC for renewable energy sources in Italy. The study also considered the consumer's viewpoint in order to clearly define the prospective benefits resulting from the installation of domestic PV systems. The results of the sensitivity analysis with respect to the variations of the manifold energy and economic parameters have highlighted what are the aspects that decision makers should consider to implement effective policies to promote renewables.

\section{Photovoltaic potential}

The combined analysis of energy and economic aspects is of basic importance for evaluating real outcomes of investments. To reach this result it was used a methodology based on the following steps:

- Architectonic aspects:

- identification of building roof surfaces (flat and slanted);

- estimation of number of floors for each building;

- shape classification of roofs.

- Energy aspects:

- estimation of the electricity produced by the PV systems as regards to each floor;

- estimation of the electricity consumed by the homeowners;

- estimation of the energy cover factor.

- Economic aspects

- evaluation of costs of the PV systems (investment costs and costs for maintenance, servicing and insurance against damage) and benefits due to the gains for the avoided bill costs, the incentives and the sold electricity;

- analysis of cash flows;

- evaluation of the economically effective and ineffective roofs;

- estimation of the energy cover factor related to the results of the economic analysis;

- sensitivity analysis for the most significant physical and economic parameters.

A definite urban scenario was assumed to calculate the produced annual PV electricity. In particular, the study was carried out on a district located in the north-west of Palermo (Sicily - Italy - Latitude $38.0^{\circ} \mathrm{N}$, Longitude $13.4^{\circ} \mathrm{E}$ ), which is shown in Fig. 1 . The methodology and the study case, which are the same that were fully described by Cellura et al. [36], are briefly summarised.

The buildings, marked by a regular orientation $\left(117^{\circ}\right.$ East of South and $153^{\circ}$ West of South), present flat and slanted roofs subdivided as follow:

- Slanted roofs: $60,145 \mathrm{~m}^{2}(55.07 \%)$.

- Flat roofs: $37,902 \mathrm{~m}^{2}(34.71 \%)$.

- Terraces: $11,017 \mathrm{~m}^{2}(10.09 \%)$.

- Others: $143 \mathrm{~m}^{2}(0.13 \%)$.

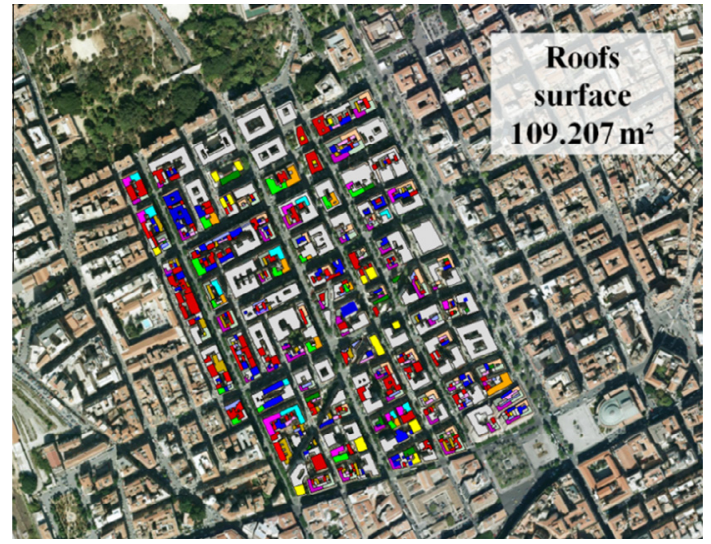

Fig. 1. The area of district occupied by buildings.

The accurate survey of the district, which was performed by means of Google Earth ${ }^{\mathrm{TM}}$, permitted to match slanted and flat roofs with the number of floors of each building.

As it is shown in Fig. 2, most of the roofs cover buildings of four floors; the majority of the slanted roofs belong to buildings of four floors whereas most of the flat floors cover buildings of eight floors. Fig. 3 shows the distribution of number of flats in the district.

The yearly electricity produced by the PV systems potentially installed on the roofs was calculated according to the roof surface available for the co-owners of each building. To obtain this figure the slanted roofs of each building were subdivided in the basic types of Table 1, which are classified in accordance with their shapes and the orientations. Fig. 4 summarises the results of the slanted roofs classification.

The classification of flat roofs of the district was based on the buildings listed in Table 2 . The buildings were selected to be representative of five classes obtained by sorting the building by their roof areas. The results are summarised in Fig. 5.

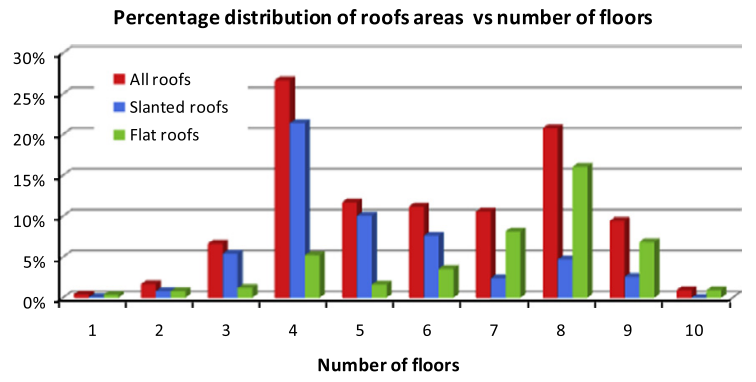

Fig. 2. Distribution of roof areas versus number of floors.

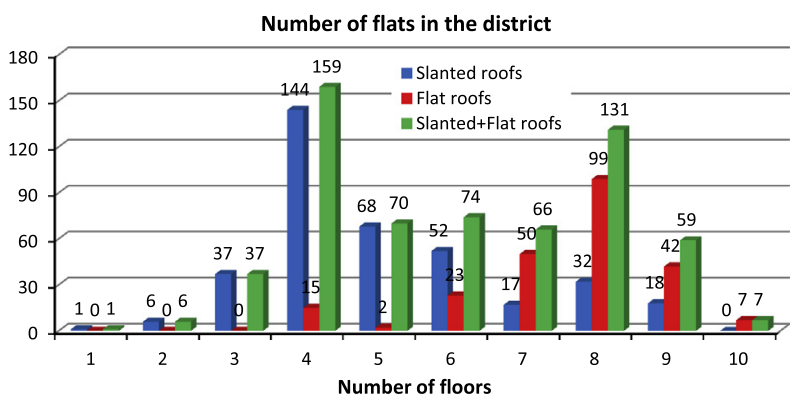

Fig. 3. Distribution of flats versus number of floors. 
Table 1

Classification of roof shapes.

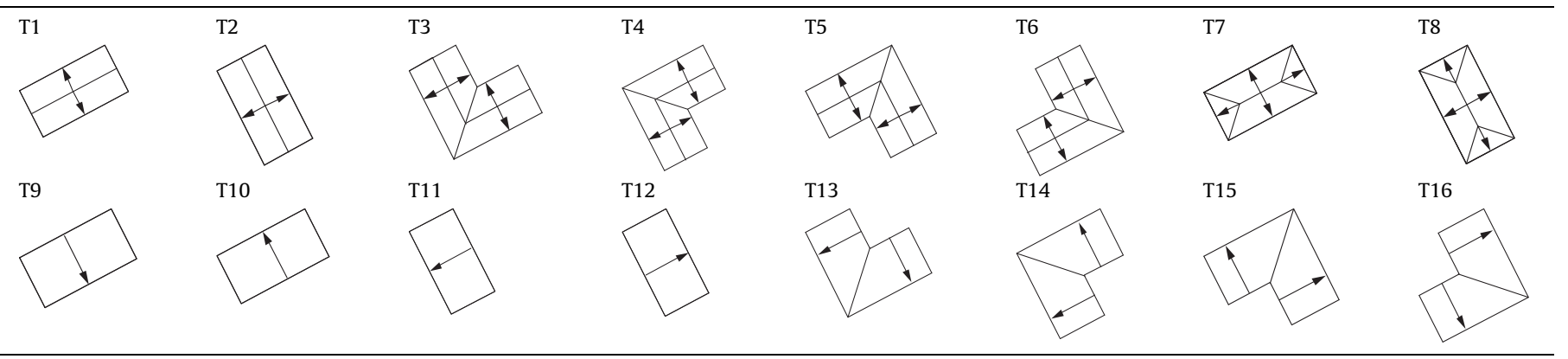

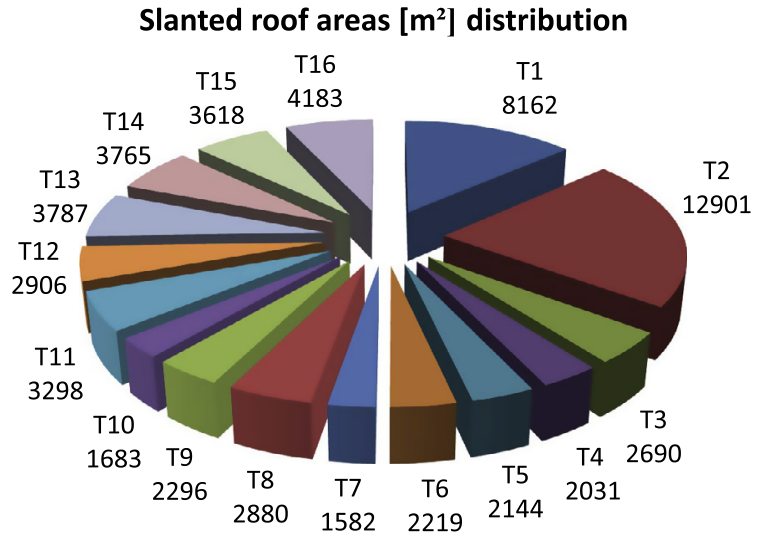

Fig. 4. Surface areas of slanted roofs.

The electricity produced by slanted and flat roofs was estimated considering that the PV arrays were built with commercial PV panels Kyocera KD210GH-2PU. To size the PV arrays the roof areas were divided by the number of floors and flats of the buildings and it was assumed that all flats had a standard surface of $162 \mathrm{~m}^{2}$, which is peculiar to the analysed district. The PV arrays were accurately sized on the basis of the dimensions of the portion of roof available for the generic co-owner of the building; the inverters were selected matching their nominal power with the size of each PV array.

The electricity calculations were repeated for each type of roof and each number of floors using PVsyst 5.06 [37]. The result of each power calculation was divided by the area of the standard flat in order to evaluate the specific value of electricity production for square meter to be accredited to any flat located in a building with any number of floors and type of roof. Such a specific value of electricity production obviously varied with the number of floors and roof type. The electricity produced by each building was evaluated by multiplying the specific value of the electricity production by the global area of the flats of the building. Eventually, the electricity produced by the entire district was calculated by summing the electrical energy produced by all buildings of the district.

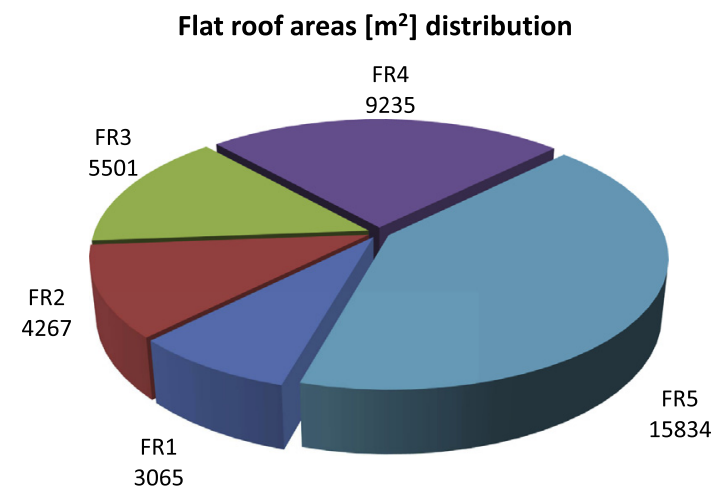

Fig. 5. Surface areas of flat roofs.

Because the performance of a PV system also depends on the tilt angle and azimuth of the collectors, the insolation can be maximised by using a surface tilt angle that exceeds the latitude of the location by $10-15^{\circ}$ during the winter months; in summer an inclination of $10-15^{\circ}$ less than the site latitude maximises the insolation [38]. PV systems are commonly mounted at an angle equal to the latitude of the location, to reach a balance between winter and summer production $[39,40]$. To obey to the rules imposed by the Italian Authorities in order to respect the aesthetical and architectonic standards for old buildings, for the slanted roofs it was also assumed that PV panels were collocated with the same pitch of the roof surface (approximately $25^{\circ}$ above the horizontal). In Table 3 some results of the energy estimation are listed.

For the flat roofs it was assumed that the panels were oriented to the south with a pitch of $30^{\circ}$, which is considered the most efficient for the city of Palermo, and installed on the roofs of the buildings of Table 2; the shadowing effect due to balustrades, elevator housings and other obstructions were also considered. In order to get a significant comparison between the energy generation of flat and slanted roofs, the PV arrays sized for the roof area of each representative buildings of Table 2 were resized in order to harness the area at disposal of the standard flat $\left(162 \mathrm{~m}^{2}\right)$. The results are shown in Table 4.

Table 2

Classification of flat roofs.

\begin{tabular}{|c|c|c|c|c|}
\hline FR1 $265 \mathrm{~m}^{2}$ & FR2 $387 \mathrm{~m}^{2}$ & FR3 $482 \mathrm{~m}^{2}$ & FR4 $717 \mathrm{~m}^{2}$ & FR5 $1394 \mathrm{~m}^{2}$ \\
\hline
\end{tabular}


Table 3

Electricity produced by slanted roofs.

\begin{tabular}{lcc}
\hline Number of floors & Total roofs area $\left(\mathrm{m}^{2}\right)$ & Electricity produced $(\mathrm{kW} h /$ year $)$ \\
\hline 1 & 64 & 5266.96 \\
2 & 934 & $41,300.53$ \\
3 & 5923 & $149,476.55$ \\
4 & 23,316 & $512,594.78$ \\
5 & 10,947 & $163,643.40$ \\
6 & 8320 & $78,456.53$ \\
7 & 2658 & $22,470.96$ \\
8 & 5158 & $44,347.64$ \\
9 & 2825 & $10,223.05$ \\
Total & 60,145 & $1,027,780.40$ \\
\hline
\end{tabular}

Table 4

Electricity produced by flat roofs.

\begin{tabular}{ccc}
\hline Number of floors & Total roofs area $\left(\mathrm{m}^{2}\right)$ & Electricity produced $(\mathrm{kW}$ h/year $)$ \\
\hline 1 & 0 & 0.00 \\
2 & 0 & 0.00 \\
3 & 0 & 0.00 \\
4 & 2319 & $43,090.88$ \\
5 & 320 & 3014.04 \\
6 & 3581 & $45,646.84$ \\
7 & 8011 & $89,973.85$ \\
8 & 15,911 & $165,323.55$ \\
9 & 6718 & $55,099.39$ \\
10 & 1042 & $7,572.44$ \\
Total & 37,902 & $409,721.00$ \\
\hline
\end{tabular}

\section{Coverage of the electricity demand}

To estimate the actual influence of each parameter on the electricity demand coverage of the district, it is required the calculation of the following gross energy cover factor $C_{P V}$ :

$C_{P V}=\frac{\sum_{j=1}^{N_{P V}} E_{P V} . j}{\sum_{j=1}^{N_{P V}} D_{j}} \cdot 100=\frac{E_{P V T o t a l}}{D_{\text {Total }}} \cdot 100$

where $N_{P V}$ represents the number of PV systems in the district and $E_{P V j}$ is the yearly PV generation of the $j$-th PV system of the district; the power demand of the $j$-th flat is $D_{J}$. $E_{P V T o t a l}$ and $D_{\text {Total }}$ are the total yearly PV generation and demand of the district, respectively. Assuming the data officially issued by TERNA [41], main Italian electricity transmission grid operator, and ISTAT, Italian National Institute of Statistics [42], Cellura et al. [36] estimated that the average electricity consumption of a household living in the standard apartment of $162 \mathrm{~m}^{2}$ corresponds to $5957.3 \mathrm{kWh}$ every year. Fig. 6 shows the results of the calculations performed taking account of the available roof areas and the number of floors of all building of the district.

\section{Gross energy cover factors $C_{P V}$ for the whole district}

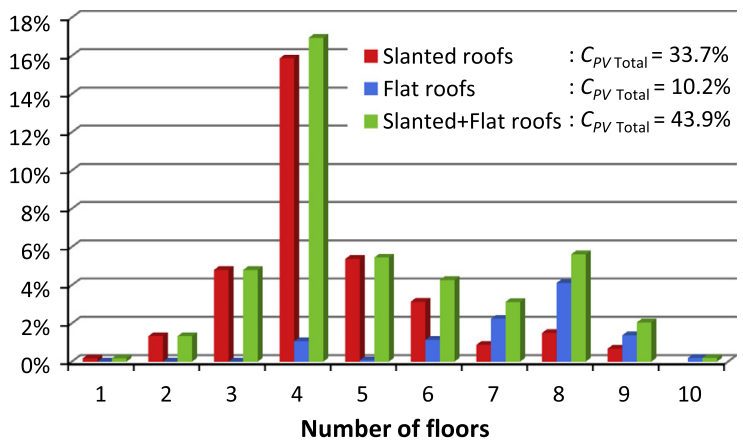

Fig. 6. Yearly gross energy cover factors for the whole district, versus the number of floors.
The results shown in Fig. 6 are definitely too optimistic because the energy was calculated without taking account of the lack of solar irradiance due to the shadowing of obstructions, possible technical malfunctioning of the PV systems which is quite likely in a urban context. Moreover it is reasonable to suppose that the energy generated by a PV system may be greater than the electricity demand of the flat, especially for the buildings with one or two floors. In this condition a part of the electrical production will be exported to the grid. Because the instantaneous perfect correspondence between demand and generation is quite improbable, a part of the demanded electricity may be not covered by the PV generation even if the energy generated is greater than the electricity demand. Such an issue, which is known as load mismatch, requires an extensive treatment and was exhaustively discussed by the authors in a different paper [43]. Nevertheless, in this paper, especially to correctly asses the economical convenience, a minimum mismatch between generated and consumed electricity was considered. Actually, the electricity consumed after sunset and before dawn will be never compensated by the energy produced by a gridconnected PV system that does not use batteries. To estimate day and night demands the value of $D_{\text {Day }}=5240.8 \mathrm{kWh} /$ year and $D_{\text {Night }}=716.5 \mathrm{~kW}$ h/year, calculated by Cellura et al., were used.

\section{Economic analysis}

The economic analysis implies the calculation of all the costs, profits and the related cash flows. The disbursements are due to the costs for investment, devices replacement, maintenance and insurance. The profits are related to the gain for the avoided electricity bill cost, sold electricity and incentives. In order to avoid that the temporary financial instability observed in Italy in the last months of 2011 improperly influenced the results of the economic analysis, the values of the economic parameters were referred to August 2011, when the effects of the oscillations of the European economic system were still moderate.

For the costs of the investment, which were obtained from the market prices of components, the cost for labour, fitter's gain and the value added tax (VAT) were considered. The electricity bills were calculated considering the difference between the bills corresponding to the electricity demand and those referred the energy consumed while the PV systems are producing electricity. The electricity tariffs issued by the AEEG - Italian Authority for electricity and gas for domestic consumers with an electricity capacity of 3 $\mathrm{kW}$ were used. Table 5 lists the data issued for the third trimester of 2011.

A selling price of $0.103 € / \mathrm{kW}$ has used to calculate the gain in selling PV electricity. An income tax of $30.22 \%$, which was estimated on the basis of the average income of the inhabitants of Palermo, was considered to value the net gain in selling the exported PV electricity. Table 6 lists the incentives paid in Italy in 2011.

The economic analysis was performed also considering:

- a yearly degradation rate in the efficiency of the PV panels equal to $1 \%$ of the nominal initial value;

- yearly maintenance and management costs estimated to be $1 \%$ of the investment cost, for flat roofs, and $2.5 \%$ for slanted roofs;

Table 5

Electricity tariff in Italy.

\begin{tabular}{llll}
\hline Energy $(€ / \mathrm{kW} \mathrm{h})$ & & Power $(€ / \mathrm{kW} /$ year $)$ & Fixed cost $(€ /$ year $)$ \\
\hline$<1800$ & 0.113146 & 14.53760 & 5.13400 \\
$1800-2640$ & 0.161676 & & \\
$2640-4440$ & 0.216276 & & \\
$>4440$ & 0.261996 & & \\
\hline
\end{tabular}


Table 6

Feed-in tariff for electricity generated by PV systems in Italy.

\begin{tabular}{lll}
\hline $\begin{array}{l}\text { Rated } \\
\text { power }\end{array}$ & August 2011 & \\
\cline { 2 - 3 } & $\begin{array}{l}\text { PV systems installed on } \\
\text { buildings } \\
{[€ / \mathrm{kW} \text { h] }}\end{array}$ & $\begin{array}{l}\text { PV systems not installed on } \\
\text { buildings } \\
{[€ / \mathrm{kW} \mathrm{h}]}\end{array}$ \\
\hline $1-3$ & 0.368 & 0.327 \\
$3-20$ & 0.339 & 0.303 \\
$20-200$ & 0.321 & 0.291 \\
$200-1000$ & 0.303 & 0.263 \\
$1000-$ & 0.280 & 0.250 \\
5000 & & \\
$>5000$ & 0.269 & 0.238 \\
\hline
\end{tabular}

- a replacement of $1 \%$ of the PV panels every year and of all inverters every five years;

- insurance costs, varying from $184.00 €$ to $307.00 €$ for PV systems with peak-power of $3 \mathrm{kWp}$ and $15 \mathrm{kWp}$, respectively;

- a yearly increasing of $5.17 \%$ in the price of electricity;

- a mean selling price of $0.103 € / \mathrm{kW} \mathrm{h}$ for the exported PV electricity;

- an inflation rate of $2.05 \%$;

- a current value of $5.20 \%$ of the discount rate;

- a VAT rate of $10 \%$ for all system devices.

All above economic factors were connected to the cash flows obtained by adding algebraically all the costs and all the profits related to the generic year for a lifetime of the investment of 20 years, which is the period of time when incentives are provided in Italy.

The results of cash flows are commonly expressed by means of some indicators, such as the net present value (NPV) and the internal rate of return (IRR), which are calculated with the following formulas:

$\mathrm{NPV}=\sum_{t=1}^{N_{y}} \frac{C_{t}}{(1+i)^{t}}-C_{0}$

$C_{0}-\sum_{t=1}^{N_{y}} \frac{C_{t}}{(1+\mathrm{IRR})^{t}}=0$

where $C_{0}$ is the initial investment cost, $C_{t}$ is the cash flow, $N_{y}$ is lifetime and $i$ is the discount rate. The use of net present value (NPV) and the benefit-to-cost ratio $(B / C)$ are recommended when the full cost of an alternative has to be considered [44]; for accept/reject investment decisions the internal rate of return (IRR) is commonly used.

In this paper, in order assess the degree of the economic convenience of the investment the authors used the NPV/PVC parameter, which is the ratio of the net present value to the present value of costs of the PV system. This parameter allows a clear and precise description of the economic behaviour of the PV installation. If NPV/PVC is positive, then the revenues surpass the disbursements over the PV system lifetime and the investment will be profitable; with a NPV/PVC of $20 \%$, if the global disbursements are 100 , at the end of the lifetime the revenues will be 120 ; if NPV/PVC is $-10 \%$, the revenues will be 90 and the investment is considered unprofitable. Moreover, very high values of NPV/PVC indicate that payback period may be quite short. Adversely, a NPV/PVC near to zero represents a critical situation where the results of the economic analysis may be abruptly upturned by small variations in the assessment of costs and benefits.

To assess the actual influence of each energy and economic parameter the solar potential generated by PV systems has to be matched with the economic analysis. This procedure permits to filter the PV electricity generated by PV systems whose installation resulted economically convenient. In this way, by eliminating the electricity produced by PV systems that are unprofitable, it is possible to reckon the amount of PV generation that must be used to realistically assess the achievement of the demand coverage for the district. Fig. 7 shows the yearly gross energy cover factors filtered with the economic criterion.

The comparison with Fig. 6 shows the significant reduction of the gross energy cover factors related to the economic convenience of the PV installations; the gross energy cover factor of the district lowers from $43.9 \%$ to $31.4 \%$, with a percentage decrement of $28 \%$.

\section{Effects of the variation of the energy and economic parameters}

The significant energy and economic parameters used to calculate the energy demand coverage and the related economic benefit can be sorted by their role in the following way:

(1) Energy parameters, which directly affect the PV potential of PV systems:

- shading due to surrounding obstructions;

- yearly degradation of PV panels efficiency.

(2) Economic parameters, on which is usually based the assessment of the profitability of PV systems:

- investment costs;

- incentives;

- discount rate;

- price of the purchased electricity;

- price of the sold electricity.

(3) Running parameters, whose effects influence the long term profitability of PV systems:

- inflation rate;

- yearly rate of PV devices replacement;

- yearly increment in the price of electricity;

- maintenance cost;

- insurance cost.

The values of some of the above parameters, like the paid incentives or the investment costs, are certain and unvarying because they were settled by law or can be exactly evaluated. Adversely, some parameters, like the efficiency degradation of PV panels or the rise in the price of electricity, can only be supposed. Other parameters, like the maintenance cost or the shadowing, require some information that is specifically related to a particular PV system and is often unavailable for all PV systems of the district. Some

Filtered gross energy cover factors $C_{P V}$ for the whole district

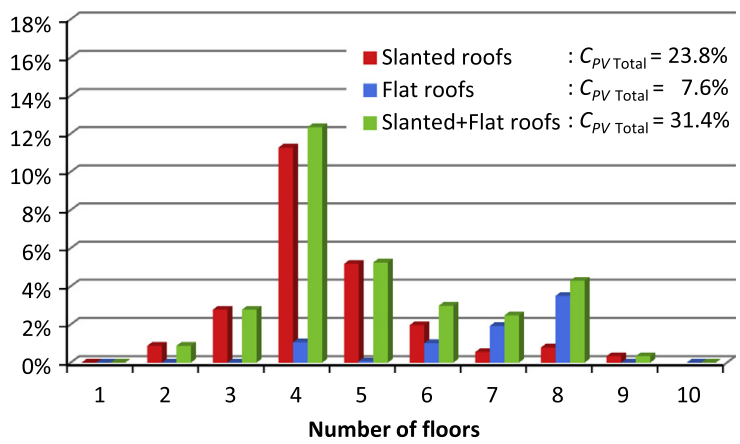

Fig. 7. Yearly gross energy cover factors for the whole district, filtered by the economic assessment, versus the number of floors. 
parameters have an irrelevant influence and for this reason a rough estimate can be sufficient. Adversely, other parameters dramatically impact on the analysis and their definition can be a crucial element of the energy and economic analysis of PV systems. To deal with the problem a sensitivity analysis, which can reveal the parameters that cause the most variation in the results, was carried out. In particular the study was approached by means of a deterministic sensitivity analysis, which involves varying the parameters over judgmentally determined ranges. Table 7 lists the analysed parameters and their variation range.

In the following sections the effect of each one of all above parameters on the gross energy cover factor and NPV/PVC of all PV systems of the district is analysed. While assessing the influence of a given parameter, the other parameters were kept to the realistic values listed in Section 4. The values of $C_{P V}$ reported in the graphs were calculated by summing only the electricity produced by the PV systems of the district that resulted economically convenient, i.e. with positive values of NPV/PVC. The values of NPV/PVC in the graphs refer to the global net present values and the present values of costs of the PV systems considered for the calculation of $C_{P V}$. Because the unprofitable PV systems were excluded, the values of NPV/PVC in the graphs are never negative; a null value of NPV/PVC means that no PV system was successful in the economic analysis.

All graphs show some common peculiarities. The gross energy cover factors slightly vary with the analysed parameter at the beginning and the end of the range of values assigned to the parameter; this is particularly evident for the PV systems installed on flat roofs that are almost insensitive for a large interval of values of the analysed parameter. There is a narrow span of values in which $C_{P V}$ shows a sudden variation, which is clearly detected by the values of the sensitivity. Only the PV electricity selling price shows a different behaviour. When the effect of the analysed parameter is still moderate, the trends of the NPC/CPV regularly vary with the parameter until a minimum value is reached. Once such a minimum is passed, almost all NPC/CPV show a swinging trend that means that the result of the economic analysis may be critical and unreliable.

The intervals of values where the most significant variations are observed always contain the values for which the gross energy cover factor of the district reaches the limit value of $17 \%$, which is the share that Italy must supply from the RES before 2020. Such an occurrence highlights the criticality of the energy strategies implemented to the RES diffusion and the need of accurately assessing the actual PV potential.

\subsection{Effect of the shading due to the surrounding obstructions}

The possibility that the collecting surfaces are shaded by surroundings obstacles has a relevant effect on the electricity demand

Table 7

Parameters range of variation.

\begin{tabular}{llc}
\hline Parameter & \multicolumn{2}{l}{ Variation range } \\
\hline Shadowing coefficient (\%) & 0 & 30 \\
PV panels efficiency degradation yearly rate (\%) & 0 & 4 \\
Investment cost multiplicative factor & 0.5 & 1.5 \\
Paid incentives multiplication factor & 0.5 & 1.5 \\
Discount rate (\%) & 0 & 12 \\
Electricity purchase price multiplication factor & 0.5 & 1.5 \\
PV electricity selling price multiplication factor & 0 & 10 \\
Inflation rate (\%) & 0 & 8 \\
PV panels replacement yearly rate (\%) & 0 & 9 \\
Electricity price yearly increment (\%) & -6 & 14 \\
Maintenance yearly cost (\%) & 0 & 7 \\
Insurance cost multiplication factor & 0 & 5 \\
\hline
\end{tabular}

coverage. When the solar radiation is deprived of its direct component, the electricity generated by PV systems drastically decreases. Actually, the shape of a site, the layout of a street, distance of neighbouring buildings and their shapes are all factors that significantly interact with the effect of shape on solar access [45]. Fig. 8a clearly depicts this condition: the electricity demand coverage reaches the limit of $17 \%$ when $11.14 \%$ of the daily solar radiation is wasted due to the shading surrounding obstacles. The sensitivity of the district gross energy cover factor to the shadowing coefficient in correspondence of this value is -1.53 . The highest value of the sensitivity $(-3.50)$ is reached with a shadowing coefficient of $12 \%$. PV systems installed on flat roofs seem to be less sensitive to the shadowing; their contribution begins to fail for values of the shadowing coefficient greater than $13.5 \%$. When the portion of the shadowed irradiance surpasses $20 \%$, about $3 \%$ of the electricity demand is covered and the sensitivity to the shadowing coefficient becomes negligible. A shading coefficient of 30\% makes ineffective all PV systems installed in the district.

The economic convenience of the investment is shown in Fig. 8b. Global NPV/PVC, which was $13.06 \%$ with no shadowing, is lowered to $6.15 \%$ when the shadowing coefficient is $11.14 \%$. About the same relative reduction is suffered by the PV systems installed on flat and slanted roofs. When the shadowing coefficient surpasses $12 \%$ the NPV/PVC swings around a mean value of $6.06 \%$. For a value of the shading coefficient greater than $27 \%$, no PV system installed on slanted roofs is economically convenient.

\subsection{Effect of the yearly degradation of PV panels efficiency}

If the efficiency of PV panels degrades in time, even the value of the gross energy cover factor of the district will lower. Such a decrease also reduces the number of profitable PV systems because the cash flows are sensitive to the yearly reduction of the benefits due the decline in the PV generation and the consequent loss of the gain for the avoided electricity bill cost, sold electricity and incentives.

As it is shown in Fig. 9a, the gross energy cover factor of the district would be $37.45 \%$ if the efficiency of the PV panels was constant. Due to the effect on the economic viability $C_{P V}$ reaches the limit of $17 \%$ when an efficiency degradation of $2.27 \%$ is assumed. Such a value, which is generally much greater than the value declared by manufacturers, may be touched if low quality PV panels are used. In correspondence of this value the sensitivity is equal to

(a) Economically filtered $C_{P V}$

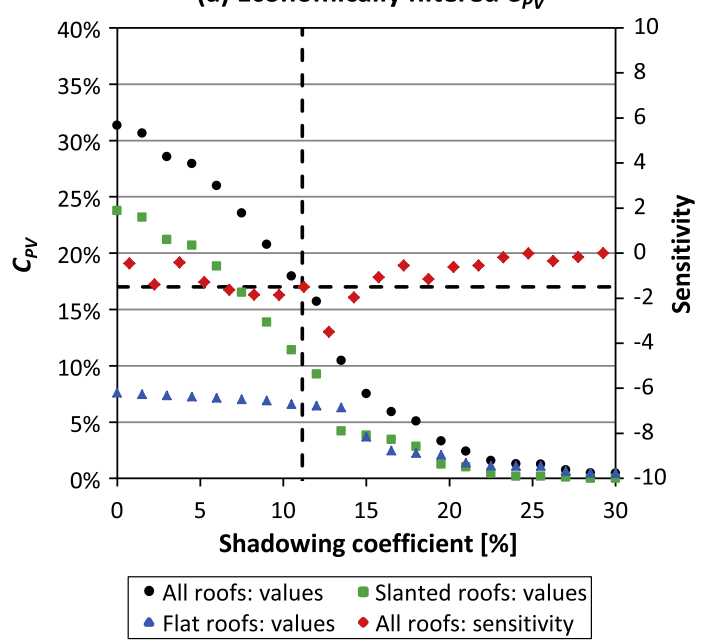

Fig. 8a. Values and sensitivity of the gross energy cover factor filtered by the economic analysis versus the shadowing coefficient. 
(b) Economically filtered NPV/PVC

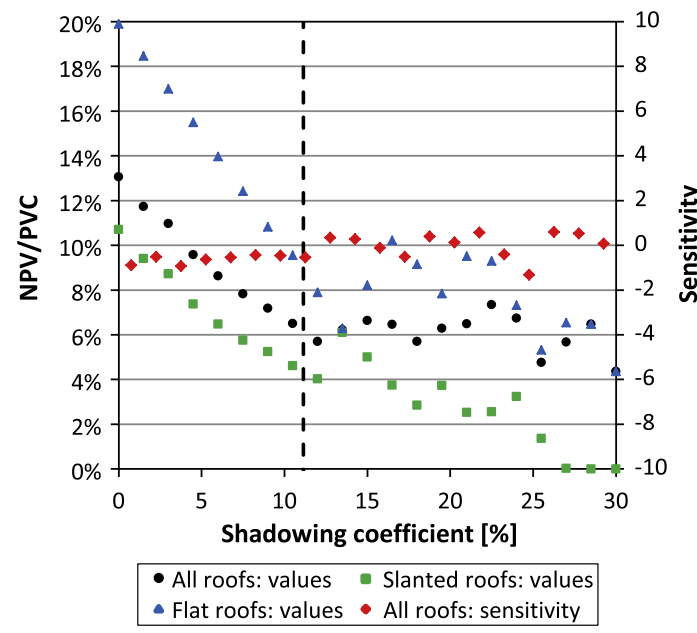

Fig. 8b. Values and sensitivity of the NPV/PVC filtered by the economic analysis versus the shadowing coefficient.

-32.66 , which is close to the highest value of -36.26 that is reached for an efficiency degradation of $2.20 \%$. The PV systems installed on slanted roofs are very sensitive to the PV panels efficiency and their contribution abruptly lowers when the yearly degradation of the efficiency surpasses $2.20 \%$.

Fig. 9b shows the economic convenience of the investment. If the efficiency of the PV panels were constant, global NPV/PVC would be $18.69 \%$. It lowers to $6.11 \%$ if the efficiency degradation is $2.27 \%$. Beyond this value NPV/PVC swings around a mean value of $6.78 \%$. No PV system installed on slanted roofs results economically convenient when the yearly degradation of the PV panels efficiency is greater than $4 \%$.

\subsection{Effect of the cost of the investment}

The investment cost is intuitively perceived as a very significant parameter. The price per peak-watt at standard testing conditions (solar irradiance of $1000 \mathrm{~W} / \mathrm{m}^{2}$, panel temperature of $25^{\circ} \mathrm{C}$, solar spectrum of mass air 1.5) [46] of the cheapest and the most expensive PV systems respectively installed on slanted and flat roofs are shown in Fig. 10.

(a) Economically filtered $C_{P V}$

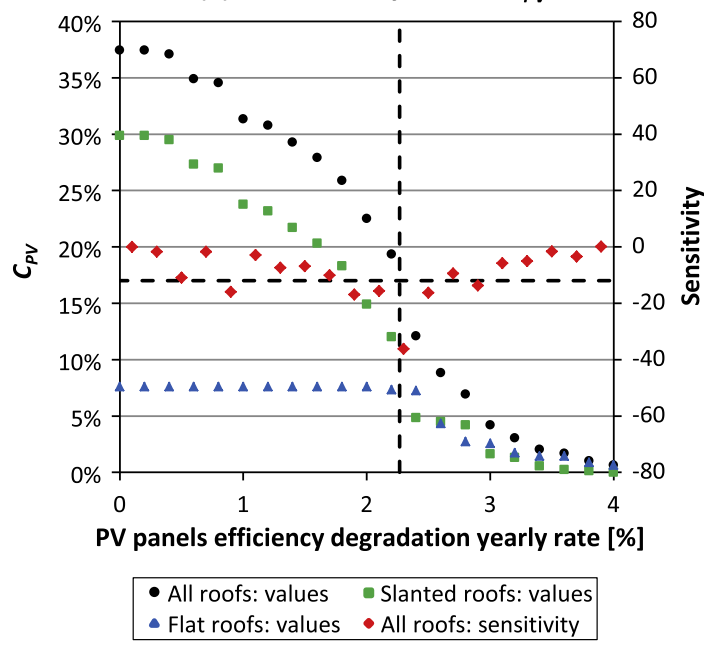

Fig. 9a. Values and sensitivity of the gross energy cover factor filtered by the economic analysis versus the yearly degradation of the PV panels efficiency. (b) Economically filtered NPV/PVC

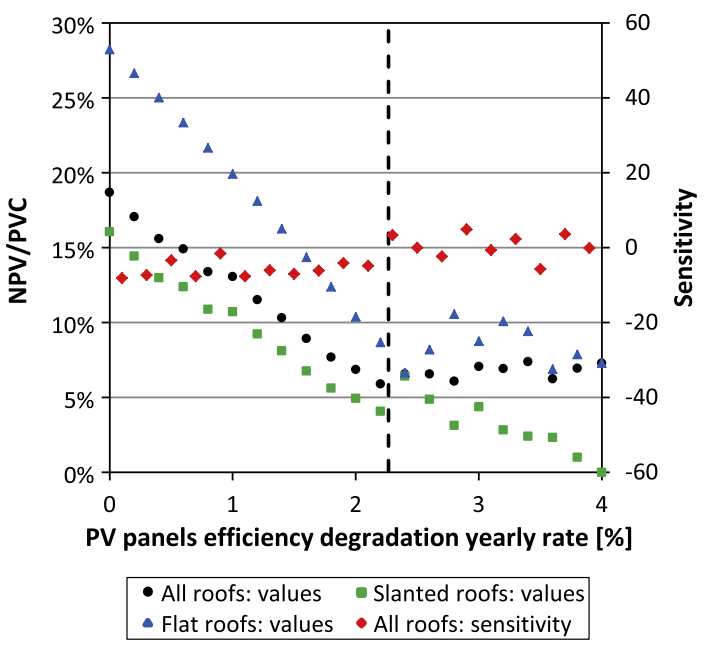

Fig. 9b. Values and sensitivity of the NPV/PVC filtered by the economic analysis versus the yearly degradation of the PV panels efficiency.

The price per peak-watt tends to increase with the height of buildings. Due to the nonlinear dependence from the size of the PV array, the cost of a PV system installed on a building with eight or nine floors may double the cost of PV systems installed on buildings with two floors. As it is shown in Fig. 10, to examine the effect of the investment cost a multiplicative factor, varying from 0.5 to 1.5 , was used for all PV systems of the district. Such a factor was multiplied by the nominal costs of the PV systems from which the values of Fig. 10 were derived.

Observing Fig. 11a it can be inferred that, if the cost of the investment is kept below $80 \%$ of the nominal cost, the gross energy cover factors is always $40.84 \%$; the PV systems on flat roofs show an almost constant value of $C_{P V}$ even if their cost of investment is $20 \%$ greater than the nominal one. $C_{P V}$ reaches the limit of $17 \%$ when the cost of the investment is $13 \%$ greater than the nominal one. In correspondence of this value the sensitivity is equal to -208.28 , which corresponds to a dramatic halving in the gross energy cover factor of the district. A multiplicative coefficient of 1.4 makes ineffective all PV systems installed on slanted roofs.

The economic convenience of the investment is shown in Fig. 11b. Global NPV/PVC, which was $19.63 \%$ with a multiplicative factor of 0.5 , is lowered to $6.66 \%$ when cost of the investment is $13 \%$ greater than the nominal one. When the cost of investment is $10 \%$ greater than the nominal one the NPV/PVC swings around

Prices per peak-watt of PV systems

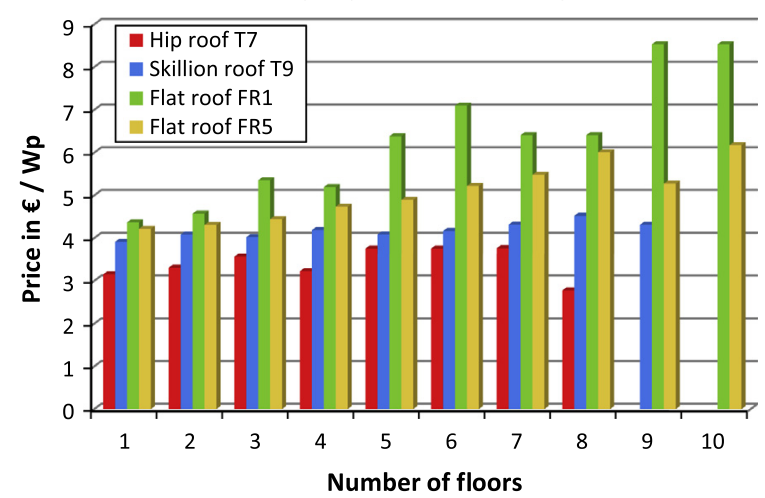

Fig. 10. Price per peak-watt of PV systems installed on slanted and flat roofs versus the number of floors. 
(a) Economically filtered $C_{P V}$

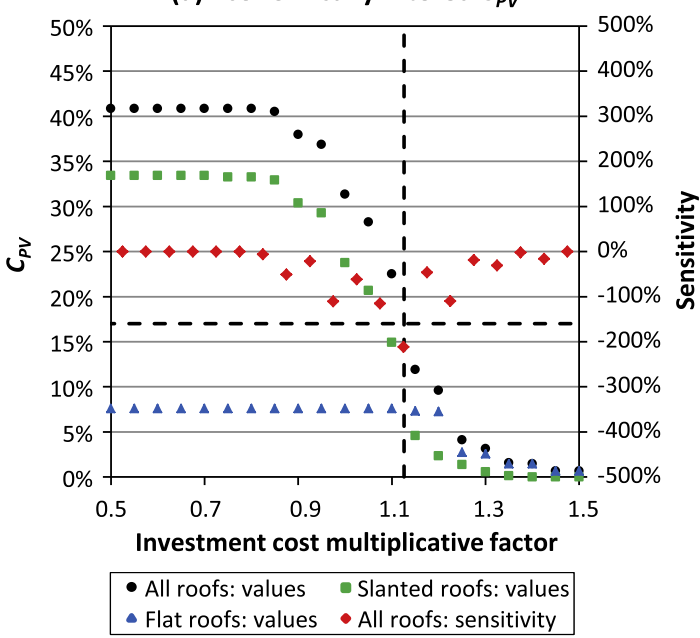

Fig. 11a. Values and sensitivity of the gross energy cover factor filtered by the economic analysis versus the investment cost.

a mean value of $6.30 \%$. For a multiplicative factor greater than 1.4 , no PV system installed on slanted roofs is economically convenient.

\subsection{Effect of the paid incentives}

The analysis of the effect of the paid incentives shows that even if they are reduced to 78\% of the incentives paid in August 2011 the gross energy cover factor of the district reaches the limit value of $17 \%$. Such an assertion has to be cautiously interpreted because other parameters, like the shading effect or the load mismatch, that certainly lower the profitability of the PV systems, were given values that are too optimistic (no shading due to the surrounding obstacles and all PV electricity used to cover daily and nightly energy demand $D_{\text {day }}, D_{\text {night }}$ ). As it can be observed in Fig. 12a, when $C_{P V}$ is $17 \%$ the sensitivity reaches the maximum value of 121.12 . If the incentives were $30 \%$ greater than the incentives paid in August 2011, the gross energy cover factor of the district would keep a constant value of $42.52 \%$.

Fig. 12b shows the effect of the paid incentives on the economic viability of the investment. The global NPV/PVC reaches the minimum value of $5.16 \%$ when the multiplication factor is 0.7 .

\section{(b) Economically filtered NPV/PVC}

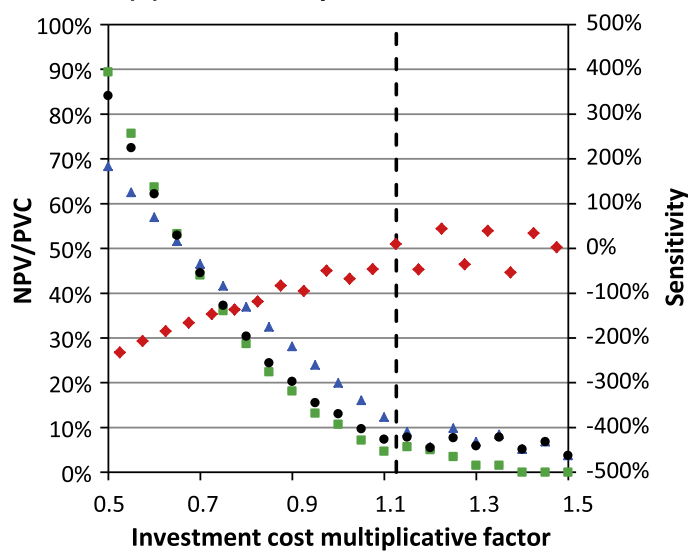

- All roofs: values Slanted roofs: values

- Flat roofs: values - All roofs: sensitivity

Fig. 11b. Values and sensitivity of the NPV/PVC filtered by the economic analysis versus the investment cost.

\subsection{Effect of the discount rate}

As it is depicted in Fig. 13a, the coverage of the $17 \%$ of electricity demand of the district is ensured when the value of the discount rate is lower than $7.9 \%$. The sensitivity corresponding to this value is -8.6 . The highest value of the sensitivity $(-9.38)$ is reached with a discount rate of $7 \%$. PV systems installed on flat roofs seem to be less sensitive to the shadowing; their contribution begins to fail for values of the discount rate greater than $9 \%$. A discount rate of $11.5 \%$ makes almost ineffective all PV systems installed on slanted roofs.

The economic convenience of the investment is shown in Fig. 13b. Global NPV/PVC, which was $31.61 \%$ with a null discount rate, is lowered to $4.93 \%$ when the shadowing coefficient is $9 \%$. When the discount rate surpasses this value the NPV/PVC swings around a mean value of 6.14 .

\subsection{The effect of the electricity purchase price}

The electricity purchase price has a significant influence because its escalation increases the benefit for the avoided electricity

(a) Economically filtered $C_{P V}$

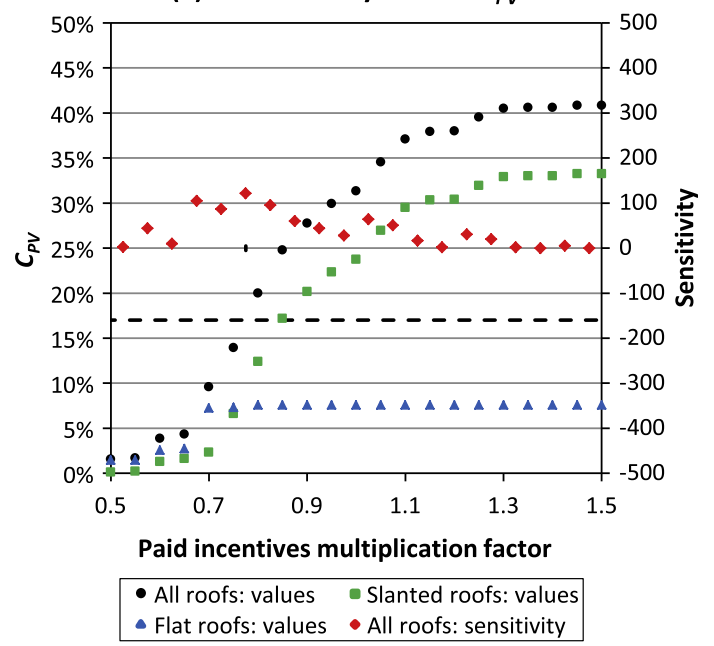

Fig. 12a. Values and sensitivity of the gross energy cover factor filtered by the economic analysis versus the paid incentives.

(b) Economically filtered NPV/PVC

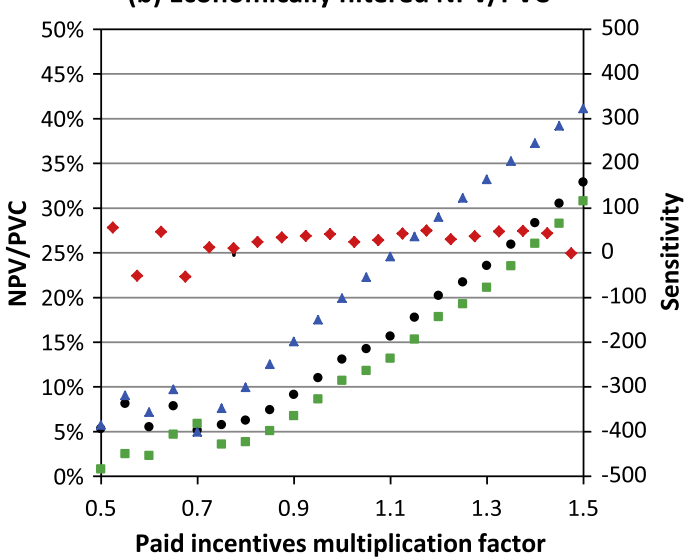

- All roofs: values - Slanted roofs: values

- Flat roofs: values - All roofs: sensitivity

Fig. 12b. Values and sensitivity of the NPV/PVC filtered by the economic analysis versus the paid incentives. 
(a) Economically filtered $C_{P V}$

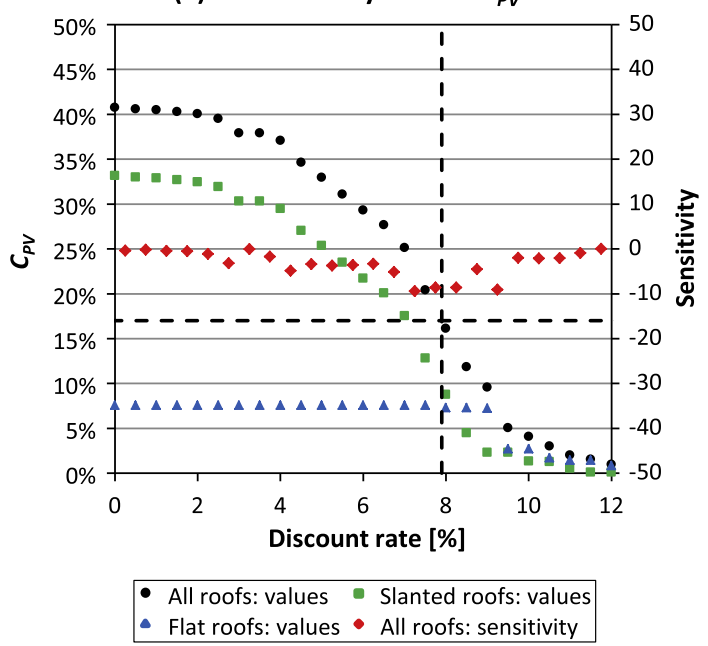

Fig. 13a. Values and sensitivity of the gross energy cover factor filtered by the economic analysis versus the discount rate.

bill costs. As it is shown in Fig. 14, to examine the effect of the investment cost a multiplicative factor, varying from 0.5 to 1.5 , was used for all PV systems of the district. Such a factor was multiplied by the price of electricity listed in Table 5 .

Observing Fig. 14a it is possible to infer that, if the electricity price was $40 \%$ higher of the price of Table 5 , the gross energy cover factors would be always $40.59 \%$; adversely, the PV systems on flat roofs are almost insensitive to the electricity price when the price is greater than $75 \%$ of the values listed in Table $5 . C_{P V}$ reaches the limit of $17 \%$ when the electricity price is $78 \%$ of the nominal one. In correspondence of this value the sensitivity is equal to 158.75 . A multiplicative coefficient of 0.5 makes ineffective all PV systems installed on slanted roofs.

The economic convenience of the investment is shown in Fig. 14b. Global NPV/PVC, which was $32.53 \%$ with a multiplicative factor of 1.5 , is lowered to $6.30 \%$ when cost of the investment is $80 \%$ of the nominal one.

\subsection{Effect of the PV electricity selling price}

The benefit for selling the electricity produced by a PV system is erroneously considered one of the major incentives to install a PV

(b) Economically filtered NPV/PVC

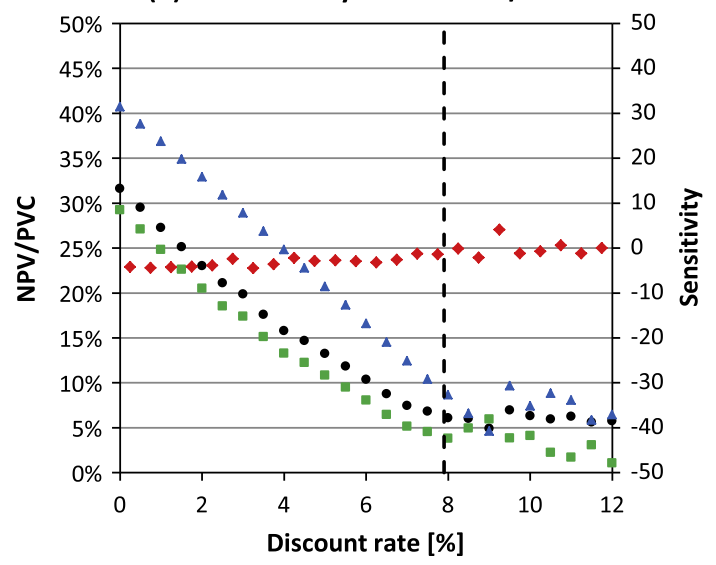

- All roofs: values - Slanted roofs: values
- Flat roofs: values

Fig. 13b. Values and sensitivity of the NPV/PVC filtered by the economic analysis versus the discount rate. (a) Economically filtered $C_{P V}$

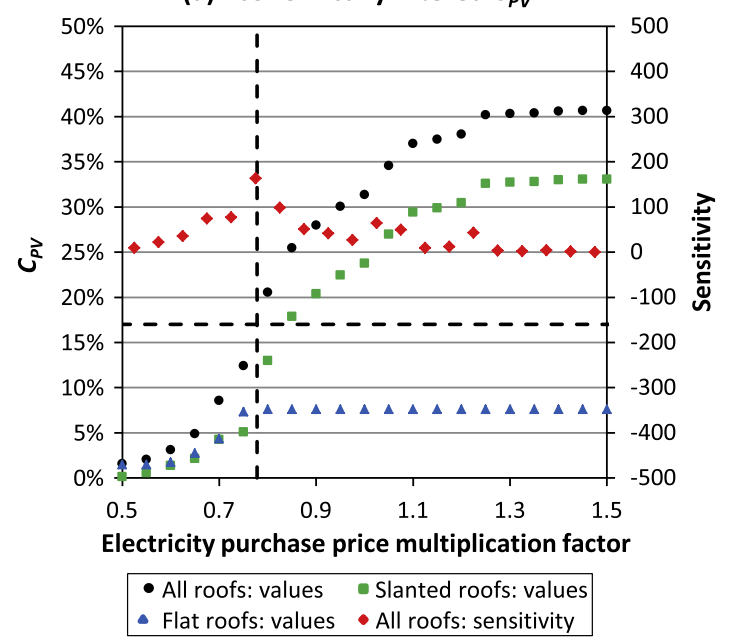

Fig. 14a. Values and sensitivity of the gross energy cover factor filtered by the economic analysis versus the electricity purchase price.

system. Unfortunately, homeowners are often induced by unprincipled promoters of RES to make money by installing on their roofs oversized PV arrays, which surpass the electrical need of the households, or harnessing the electricity generated by PV systems located in farmlands. These ventures are rarely destined to be successful because the price of the sold electricity is smaller than the purchase price and the gain is also taxed.

Fig. 15a clearly confirms that the effect of selling PV electricity is quite irrelevant even if the selling price is decoupled. The gross energy cover factor that would be $31.10 \%$ if the selling price was zero, becomes $32.04 \%$ when the selling price is hypothetically multiplied tenfold. As it is shown in Fig. 15b, a decoupled price of the sold PV electricity increases the global NPV/PVC from $13.06 \%$ to $16.97 \%$ with a relative increment of less than $30 \%$.

\subsection{Effect of the inflation rate}

The inflation rate is one of the economic parameters that mostly worry long term investors because they fear that the future disbursements will be more onerous than the budgeted costs. Due

\section{(b) Economically filtered NPV/PVC}

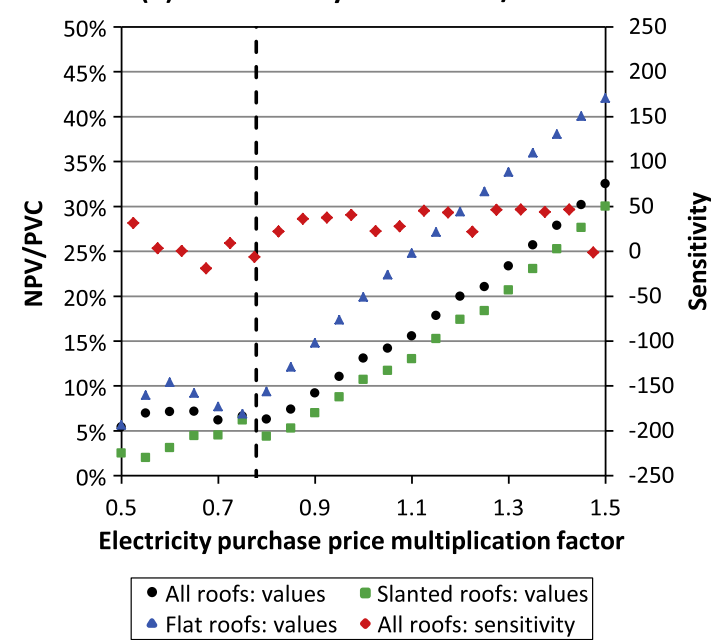

Fig. 14b. Values and sensitivity of the NPV/PVC filtered by the economic analysis versus the electricity purchase price. 
to the importance of this parameter, all future costs considered in the cash flows were updated with a supposable value of the inflation rate.

As it is shown in Fig. 16a, even small values of the inflation rate affects the gross energy cover factor. A value of $4.28 \%$ makes $C_{P V}$ equal to the limit value of $17 \%$. An inflation rate of $7.8 \%$, which is a probable event during a financial crisis, almost cancels the gross energy cover factor of the district. The sensitivity in correspondence of an inflation rate of $4.28 \%$ is -16.7 , which is close to the highest value (-18.95).

Fig. 16b shows the economic convenience of the investment. Global NPV/PVC, which would be $19.63 \%$ with a null inflation rate, decreases to the minimum value of $6.0 \%$ when the inflation rate is $4.8 \%$. When the inflation rate surpasses $7.2 \%$, no PV system installed on flat roofs results profitable.

\subsection{Effect of the yearly rate of PV devices replacement}

The long exposure to bad weather conditions enhances the probability of damages for the PV devices. For this reason it was assumed the replacement of all inverters every 5 years and the yearly

\section{(a) Economically filtered $C_{p V}$}

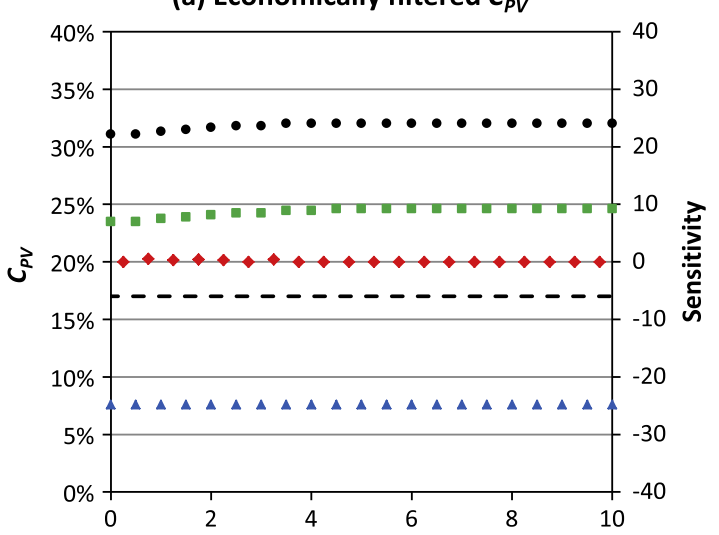

PV electricity selling price multiplication factor

$$
\begin{aligned}
& \text { - All roofs: values - Slanted roofs: values } \\
& \text { - Flat roofs: values - All roofs: sensitivity }
\end{aligned}
$$

Fig. 15a. Values and sensitivity of the gross energy cover factor filtered by the economic analysis versus the PV electricity selling price.

\section{(b) Economically filtered NPV/PVC}

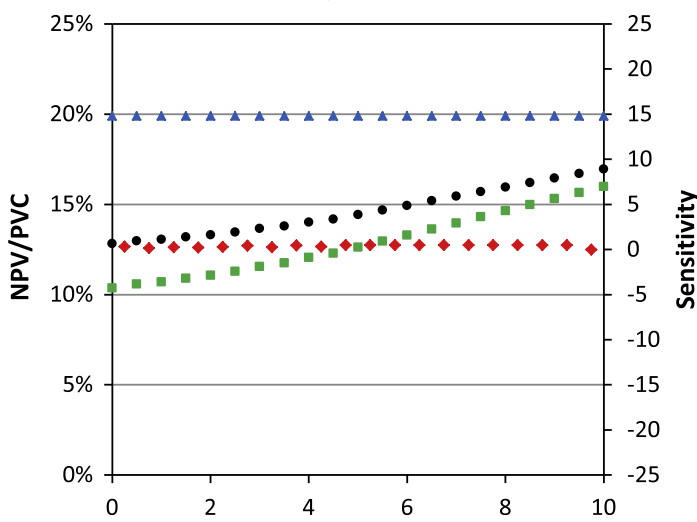

PV electricity selling price multiplication factor

$$
\begin{aligned}
& \text { - All roofs: values - Slanted roofs: values } \\
& \text { - Flat roofs: values - All roofs: sensitivity }
\end{aligned}
$$

Fig. 15b. Values and sensitivity of the NPV/PVC filtered by the economic analysis versus the PV electricity selling price.

substitution of a percentage of the installed PV panels. Whereas there is a founded information on the lifetime of inverters, the life expectancy of PV panels is less predictable because may vary for many reasons that also depends on the technological quality of the devices and the climatic peculiarities of the site where the panels are placed. The effect of the inflation rate was considered in the future price of the replaced PV panels. Such an effect should be counterbalanced by the quick reduction in the prices of the PV panels that has been observed in the recent past and that is destined to fade in the future. Because it is almost impossible to forecast the variation in the PV panels prices in the next 20 years, this aspect was neglected and for this reason the results can be considered more conservative.

Fig. 17a shows that yearly rate of PV panels replacement strongly affects the gross energy cover factor of the district that reaches the limit value of $17 \%$ with a replacement rate of $3.20 \%$. The sensitivity, which measures -15.32 , is very close to the highest value of -15.91. All PV systems installed on slanted roofs become ineffective for a replacement rate greater than $7 \%$. The PV systems installed on flat roof seem to be almost insensitive for values of the replacement rate less than $5.5 \%$.

(a) Economically filtered $C_{P V}$

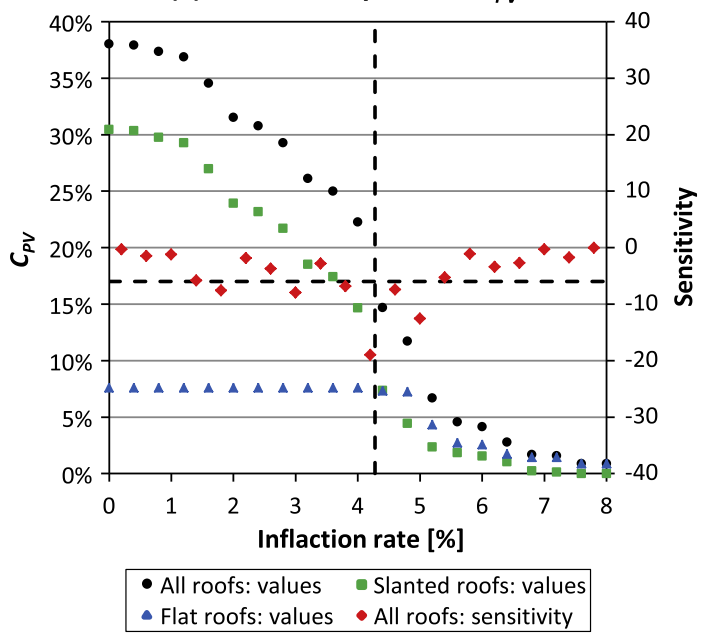

Fig. 16a. Values and sensitivity of the gross energy cover factor filtered by the economic analysis versus the inflation rate.

\section{(b) Economically filtered NPV/PVC}

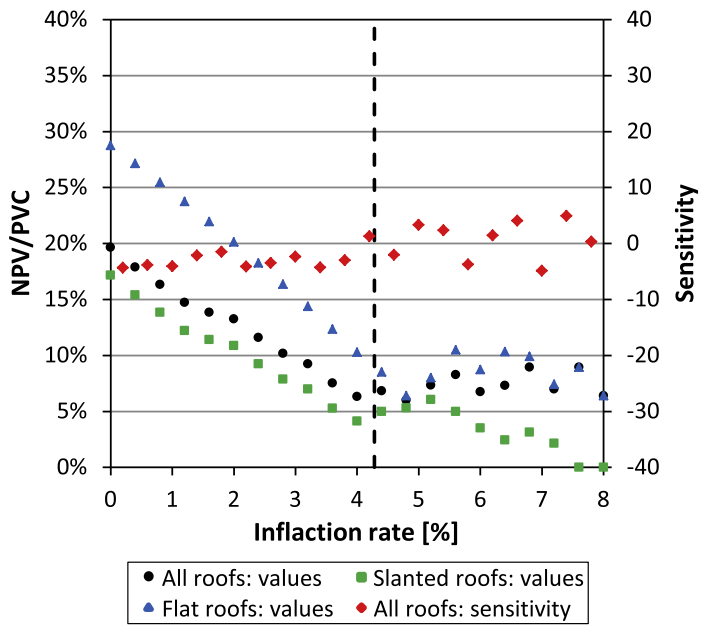

Fig. 16b. Values and sensitivity of the NPV/PVC filtered by the economic analysis versus the inflation rate. 
The economic convenience of the investment is shown in Fig. 17b. Global NPV/PVC, which is $16.04 \%$ with a null value of the replacement rate, is lowered to $3.85 \%$ when the shadowing coefficient is $5.5 \%$. A greater relative reduction is suffered by the PV systems installed on flat roofs. For a value of the shading coefficient greater than $7.5 \%$, no PV system installed on slanted roofs is economically convenient.

\subsection{Effect of the yearly increment in the price of electricity}

Due to the ever-increasing need of energy the rise of the electricity price seems to be relentless; this occurrence makes PV systems more profitable in the long term assessment. As it is depicted in Fig. 18a, the electricity demand coverage reaches the limit of $17 \%$ when rise of the electricity price is $1.55 \%$ every year. The sensitivity of the district gross energy cover factor in correspondence of this value is 8.63. PV systems installed on flat roofs seem to be less sensitive to the shadowing; their contribution begins to fail for values of the yearly increment of the electricity price lower than $1 \%$.

Fig. 18b shows the economic convenience of the investment.Global NPV/PVC is 5.95\% with a null rise of the electricity price. Only supposing for the electricity price an unrealistic decrement of $6 \%$ it is possible to reset the NPV/PVC.

\subsection{Effect of the yearly maintenance cost}

As it is depicted in Fig. 19a, if the yearly maintenance cost reaches $3,84 \%$ of the initial investment costs, the electric production generated by PV systems of whole district covers $17 \%$ of electricity demand of the district. The sensitivity of the district gross energy cover factor in correspondence of this value is - 12.57. A maximum value of the sensitivity of -25.76 is reached for a yearly maintenance cost of $4.17 \%$ of the initial investment costs. The PV systems installed on flat roofs abruptly reduce their contribution when the yearly maintenance cost surpasses $3 \%$.

The related economic convenience is pointed out by Fig. 19b. The trends of NPV/PVC are quite similar for all kinds of roof. In correspondence of a yearly maintenance cost of $3.84 \%$ the global NPV/ PVC reaches a value of $4.80 \%$. All PV systems become unprofitable when the yearly maintenance cost is $7 \%$ of the initial investment costs.

(a) Economically filtered $C_{P V}$

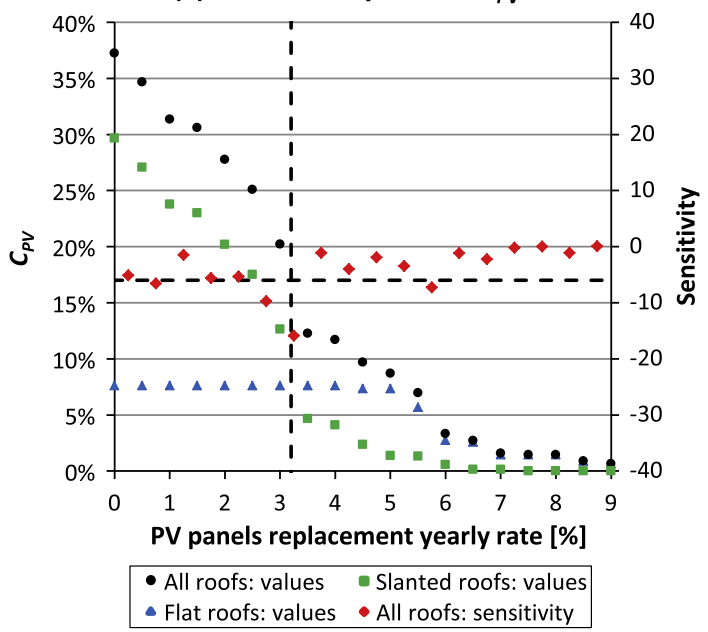

Fig. 17a. Values and sensitivity of the gross energy cover factor filtered by the economic analysis versus the yearly rate of PV panels replacement. (b) Economically filtered NPV/PVC

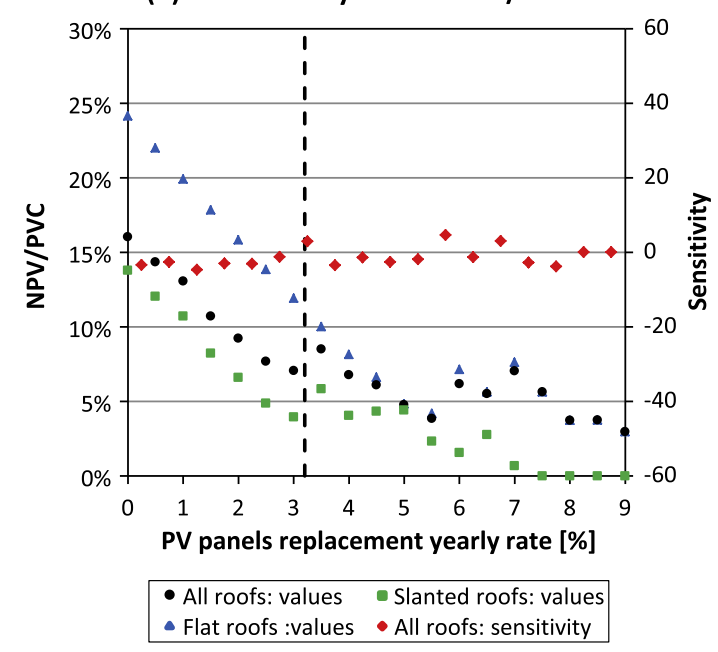

Fig. 17b. Values and sensitivity of the NPV/PVC filtered by the economic analysis versus the yearly rate of PV panels replacement.

(a) Economically filtered $C_{P V}$

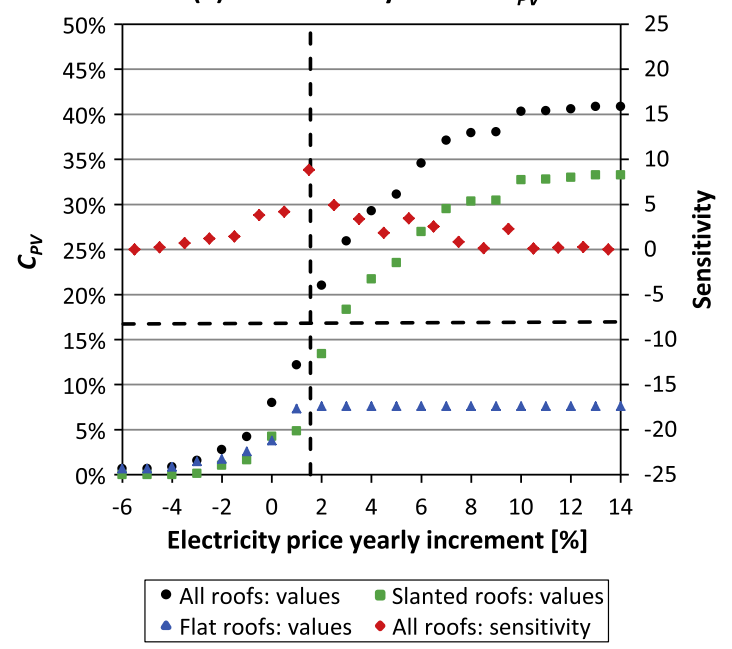

Fig. 18a. Values and sensitivity of the gross energy cover factor filtered by the economic analysis versus the yearly increment in the electricity price.

(b) Economically filtered NPV/PVC

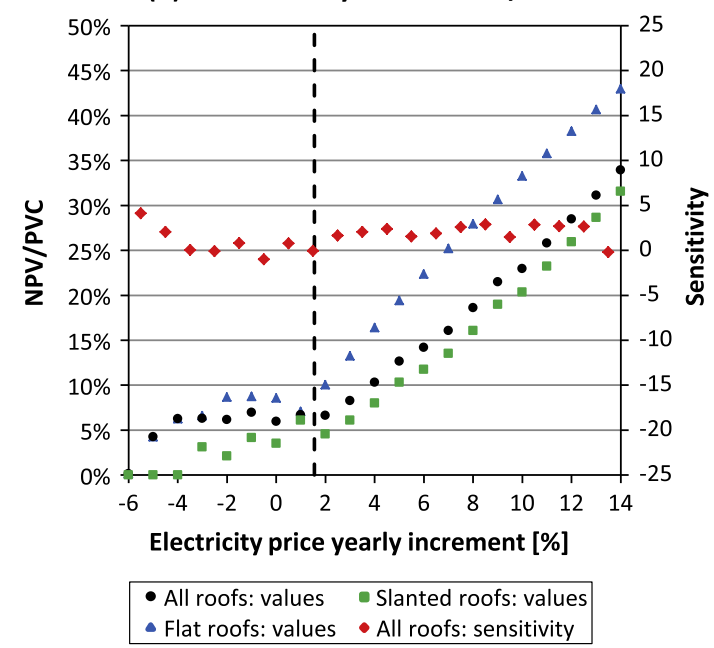

Fig. 18b. Values and sensitivity of the NPV/PVC filtered by the economic analysis versus the yearly increment in the electricity price. 


\subsection{Effect of the yearly insurance cost}

PV systems may damage the underneath persons and things if they fall from the roof due to the wind or a structural failure. For this reason it is appropriate to take out an insurance against these risks. To examine the effect of the yearly insurance cost a multiplicative factor, varying from 0 to 5 , was used for all PV systems of the district. This factor was multiplied by the insurance costs indicated in Section 4 . The coverage of $17 \%$ the electricity demand is guaranteed even if the insurance costs are almost doubled. Actually, as depicted in Fig. 20a, with a multiplication factor of 2.04 the gross energy cover facto of the district reaches the limit value of $17 \%$. In correspondence of this value the sensitivity is - 24.36. The sensitivity reaches its highest value of -35.02 when the multiplicative factor is 1.88 .

Fig. 20b shows the economic convenience of the investment. Global NPV/PVC, which would be $22.99 \%$ with no insurance cost, sharply decreases to the value of $3.94 \%$ when the insurance cost

(a) Economically filtered $C_{P V}$

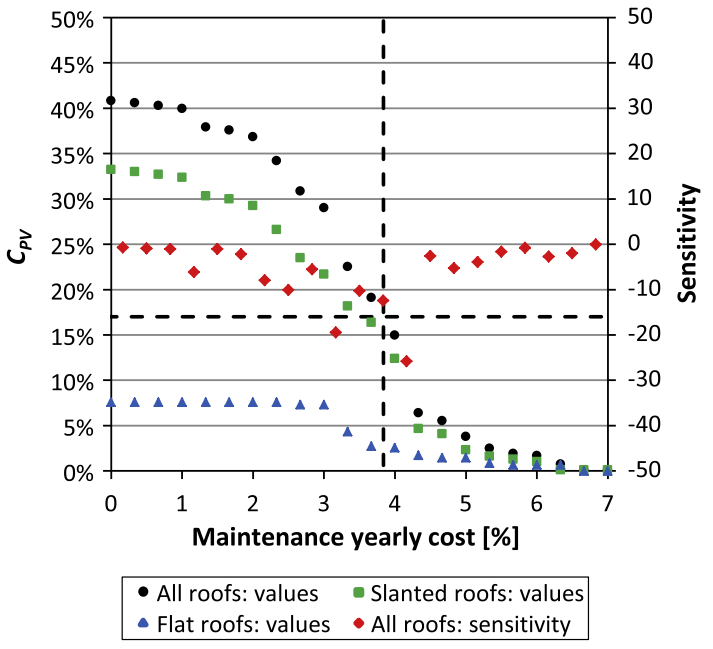

Fig. 19a. Values and sensitivity of the gross energy cover factor filtered by the economic analysis versus the yearly maintenance cost.

\section{(b) Economically filtered NPV/PVC}

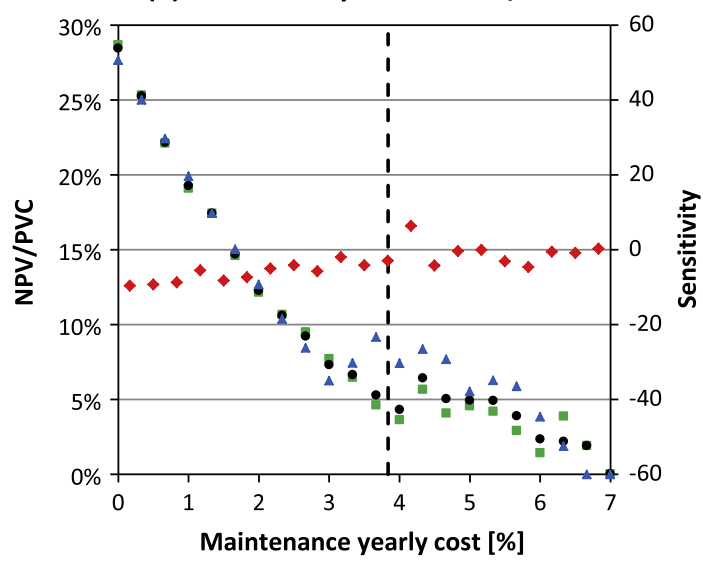

- All roofs: values - Slanted roofs: values

- Flat roofs: values - All roofs: sensitivity

Fig. 19b. Values and sensitivity of the NPV/PVC filtered by the economic analysis versus the yearly increment in the maintenance cost (a) Economically filtered $C_{P V}$

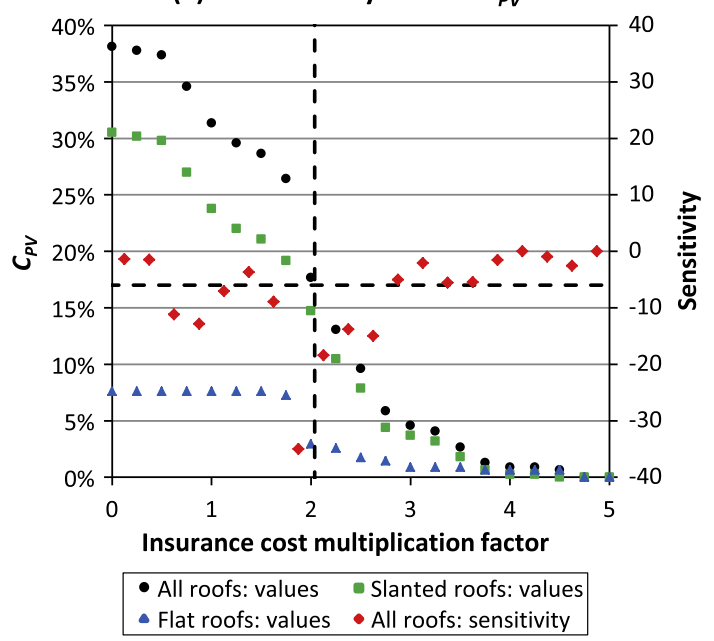

Fig. 20a. Values and sensitivity of the gross energy cover factor filtered by the economic analysis versus the yearly insurance cost.

(b) Economically filtered NPV/PVC

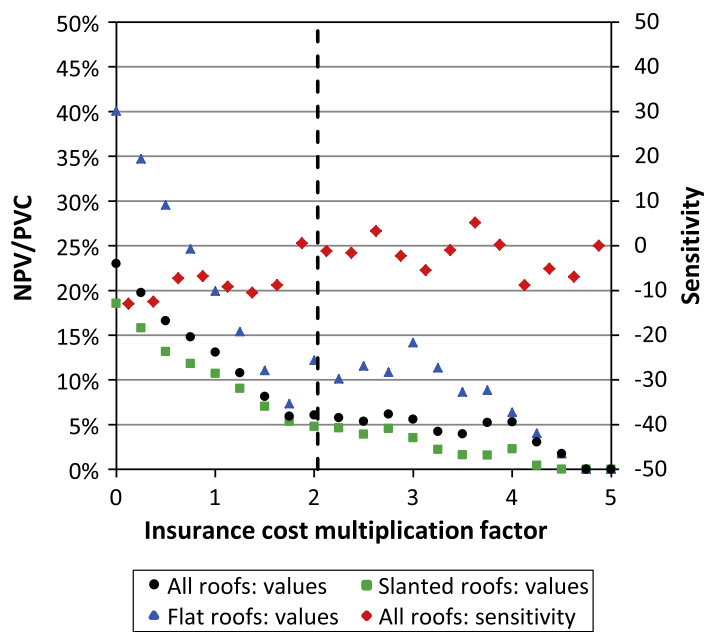

Fig. 20b. Values and sensitivity of the NPV/PVC filtered by the economic analysis versus the yearly increment in the insurance cost.

is 3.5 times the nominal value of Section 4. When the multiplicative factor surpasses 4.5 , no PV system installed on flat roofs results profitable.

\section{Results and discussion}

Table 8 summarises the values of all analysed parameters in correspondence of which the energy cover factor of the district is $17 \%$. In the table are also listed the corresponding values of NPV/ PVC and of the sensitivity of $C_{P V}$ and NPV/PVC.

A positive value of the sensitivity of $C_{P V}$ means that the rise of the analysed parameter will increase the energy cover factor of the district. In this case the value of the analysed parameter listed in Table 8 represents the minimum value that permits to reach $C_{P V}=17 \%$. The opposite is for a negative value of the sensitivity of the gross energy cover factor and the listed values are the maximum values that should be never surpassed.

As it was predictable, the high values of the sensitivity related to the investment cost, paid incentives and purchase price of the electricity, confirm the relevant influence of this parameters. Nev- 
Table 8

Values of the parameters and sensitivities in correspondence of $C_{P V}=17 \%$.

\begin{tabular}{|c|c|c|c|c|c|}
\hline \multirow[t]{2}{*}{ Parameter } & & \multicolumn{2}{|c|}{$\begin{array}{l}\text { Gross energy } \\
\text { cover factor }\end{array}$} & \multicolumn{2}{|c|}{$\begin{array}{l}\text { Investment } \\
\text { profitability }\end{array}$} \\
\hline & & $\begin{array}{l}C_{P V} \\
(\%)\end{array}$ & Sensitivity & $\begin{array}{l}\text { NPV/ } \\
\text { PVC } \\
(\%)\end{array}$ & Sensitivity \\
\hline Shadowing coefficient & $11.14 \%$ & 17 & -1.53 & 6.15 & -0.53 \\
\hline $\begin{array}{l}\text { PV panels efficiency } \\
\text { degradation yearly } \\
\text { rate }\end{array}$ & $2.27 \%$ & 17 & -32.66 & 6.11 & 1.91 \\
\hline $\begin{array}{l}\text { Investment cost } \\
\text { multiplicative factor }\end{array}$ & 1.13 & 17 & -208.28 & 7.60 & 8.88 \\
\hline $\begin{array}{l}\text { Paid incentives } \\
\text { multiplication factor }\end{array}$ & 0.78 & 17 & 121.12 & 6.01 & 9.85 \\
\hline Discount rate & $7.90 \%$ & 17 & -8.60 & 6.23 & -1.06 \\
\hline $\begin{array}{l}\text { Electricity purchase } \\
\text { price multiplication } \\
\text { factor }\end{array}$ & 0.78 & 17 & 158.75 & 6.44 & -4.61 \\
\hline $\begin{array}{l}\text { PV electricity selling } \\
\text { price multiplication } \\
\text { factor }\end{array}$ & - & 17 & - & - & - \\
\hline Inflation rate & $4.28 \%$ & 17 & -16.70 & 6.66 & 0.63 \\
\hline $\begin{array}{l}\text { PV panels replacement } \\
\text { yearly rate }\end{array}$ & $3.20 \%$ & 17 & -15.32 & 7.65 & 2.51 \\
\hline $\begin{array}{l}\text { Electricity price yearly } \\
\text { increment }\end{array}$ & $1.55 \%$ & 17 & 8.63 & 6.66 & 0.01 \\
\hline Maintenance yearly cost & $3.84 \%$ & 17 & -12.57 & 4.80 & -2.80 \\
\hline $\begin{array}{l}\text { Insurance cost } \\
\text { multiplication factor }\end{array}$ & 2.04 & 17 & -24.36 & 6.00 & -1.08 \\
\hline
\end{tabular}

ertheless the values of the parameters listed in the table can be varied into ranges that are still enough large without the risk of reaching a value of $C_{P V}$ less than $7 \%$. A limit value of the shadowing coefficient of $11.14 \%$ represents a condition that is not very far from the reality especially for the PV systems installed in urban areas. An inflation rate of $4.28 \%$ and a discount rate of 7.90 are a possible occurrence during a financial crisis. The effect of the variation of the PV electricity selling price is quite irrelevant.

Even if the values of the parameters listed in Table 8 can provide some useful information about the acceptable range of their variation, it is appropriate to point out that they refer to the individual effect of each single parameter. Because the nature of the problem is not linear, the values of the listed sensitivities should not be used to calculate the joint effect of two or more parameters.

Moreover, the showed results are strongly correlated with the values assumed by the parameters that are kept fixed while the generic analysed parameter is varied to assess the specific sensitivity. Some parameters, such as the paid incentives and the sold energy price, may be influenced by the energy strategies adopted by each government during the time, whereas other parameters, like the discount rate and the inflation rate, may vary due to the economic situation of each country. Some parameters, such as the efficiency degradation, PV panel replacement and maintenance cost, are more related to technology aspects, while the investment and insurance costs are supposed to be strongly influenced by the promising dissemination of PV systems. The effect of the shadowing coefficient is not related to a specific region because it is more specifically influenced by the urban context, and the trend of the energy price increment seems to be destined to keep values that are quite similar in all industrialised nations. Nevertheless, even if the results of the present study cannot be considered numerically valid for PV systems installed on roofs of building located in regions that are quite different from the Italian city of Palermo, they can provide some valid and general information on the qualitative effects of the economic and energy parameters involved in the assessment of the effectiveness of PV systems installed in urban areas.

\section{Conclusions}

The achievement of the "20-20-20" target charged by the European Union (EU) is strictly linked to the profitability of the PV systems, especially in the urban areas where the available buildings' roof surfaces have to be divided into equal portions among several co-owners. The share of energy from renewable sources in gross final consumption of energy in 2020 would be at least $17 \%$ of the total for the Italian case.

The presented study provides a review of the main energy and economic parameters involved in the assessment of the coverage of the electricity demand of a district in a South-Italy city and focused on economic convenience for the homeowners of installing PV systems. A sensitivity deterministic analysis, in which the analysed parameters were varied over determined ranges, was carried out. The effects of the parameters on the gross energy cover factor of the district and on the ratio of the net present value to the present value of costs of all PV systems of the district, were analysed.

After the assessment of the PV potential of the district roof surfaces that are suitable for PV systems in accordance with the shape, orientation and number of floors of the buildings, the authors carried out an accurate economic analysis. The aim was to define the actual amount of electricity that was produced by economically advantageous PV systems and, contextually, the level of the economic benefits that are generated. The parameters involved in the study were the shading due to surrounding obstructions, the yearly degradation of PV panels efficiency, the investment costs, the paid incentives, the discount rate, the price of the purchased electricity, the price of the sold electricity. The inflation rate, the yearly rate of PV devices replacement, the yearly increment in the price of electricity, the maintenance cost and the insurance cost. It was analysed the effect of each one of the above factors and the values that determine the achievement of a given electricity demand coverage and the consequent rate of the economic benefits were calculated.

If the effect of each energy parameter is individually considered it can be claimed that gross energy cover factor of the analysed district is greater than $17 \%$ if shading due to surrounding obstructions is less than $11.14 \%$ and the yearly degradation of PV panels efficiency is less than $2.27 \%$. Dealing with the parameters on which the profitability is usually assessed, the study has shown that the limit value of $C_{P V}$ is kept if the discount rate is less than $7.90 \%$, the investment costs do not surpass of $13 \%$ the nominal ones used in this analysis. Moreover it is required that the incentives do not lower under $78 \%$ of the values paid in Italy on August 2011and the purchase price of the electricity is at least $78 \%$ of the present one. The inflation rate and the yearly rate of PV panels replacement should be less than $4.28 \%$ and $3.20 \%$, respectively. A minimum value of $1.55 \%$ is required for the yearly increment in the electricity price. The maintenance cost should not surpass $3.84 \%$ of the investment cost and the cost for insurance should not be more than 2.04 times the nominal values used in the study. The results also showed that the PV electricity selling price marginally affects the electricity demand coverage of the district. This result confirms the opinion that installing PV systems only to make money by selling the produced electricity may be a risky investment.

Even if the validity of the presented results is related to the analysed district, the study can be used by the PV systems designers to control the impact of the deviation of the main parameters that affect the economic profits connected with the installation of PV systems. Moreover, the study may help decision-makers to evaluate the role played by the variation of such parameters in order to implement effective energy policies that allow the achievement of the predicted shares of electricity demand coverage. 


\section{References}

[1] Hofierka J, Kaňuk J. Assessment of photovoltaic potential in urban areas using open-source solar radiation tools. Renew Energy 2009;34:2206-14.

[2] Vardimon R. Assessment of the potential for distributed photovoltaic electricity production in Israel. Renew Energy 2011;36:591-4.

[3] Ordóñez J, Jadraque E, Alegre J, Martínez G. Analysis of the photovoltaic solar energy capacity of residential rooftops in Andalusia (Spain). Renew Sust Energy Rev 2010;14:2122-30.

[4] Izquierdo S, Rodrigues M, Fueyo N. A method for estimating the geographical distribution of the available roof surface area for large-scale photovoltaic energy-potential evaluations. Solar Energy 2008;82:929-39.

[5] Wiginton LK, Nguyen HT, Pearce JM. Quantifying rooftop solar photovoltaic potential for regional renewable energy policy. Computers Environ Urban Syst 2010;34:345-57.

[6] Nguyen HT, Pearce JM. Estimating potential photovoltaic yield with r.sun and the open source geographical resources analysis support system. Solar Energy 2010;84:831-43.

[7] Viana TS, Rüther R, Martins FR, Pereira EB. Assessing the potential of concentrating solar photovoltaic generation in Brazil with satellite-derived direct normal irradiation. Solar Energy 2011;85:486-95.

[8] Šúri M, Huld TA, Dunlop ED, Ossenbrink HA. Potential of solar electricity generation in the European Union member states and candidate countries. Solar Energy 2007;81:1295-305.

[9] Pelland S, Poissant Y. An evaluation of the potential of building integrated photovoltaics in Canada. In: 31st Annual conference of the solar energy society of Canada (SESCI), Aug. 20-24th 2006, Montréal, Canada.

[10] Kaan H, Reijenga T. Photovoltaics in an architectural context. Prog Photovolt: Res Appl 2004;12:395-408.

[11] Hachem C, Athienitis A, Fazio P. Evaluation of energy supply and demand in solar neighbourhoods. Energy Build 2012;49:335-47.

[12] Strzalka A, Alam N, Duminil E, Coors V, Eicker U. Large scale integration of photovoltaics in cities. Appl Energy 2012;93:413-21.

[13] Van der Zwaan B, Rabl A. The learning potential of photovoltaics: implications for energy policy. Energy Policy 2004;32:1545-54.

[14] Hongbo R, Weijun G, Yingjun R. Economic optimization and sensitivity analysis of photovoltaic system in residential buildings. Renew Energy 2009;34:883-9.

[15] Li Z, Boyle F, Reynolds A. Domestic application of solar PV systems in Ireland: the reality of their economic viability. Energy 2011;36:5865-76.

[16] Martinez-Cesena EA, Azzopardi B, Mutale J. Assessment of domestic photovoltaics systems based on real option theory. Prog Photovolt: Res Appl 2012.

[17] Chong WT, Naghavi MS, Poh SC, Mahlia TMI, Pan KC. Techno-economic analysis of a wind-solar hybrid renewable energy system with rainwater collection feature for urban high-rise application. Appl Energy 2011;88:4067-77.

[18] Lüthi S. Effective deployment of photovoltaics in the Mediterranean countries: balancing policy risk and return. Solar Energy 2010;84:1059-71.

[19] Poullikkas A. Parametric cost-benefit analysis for the installation of photovoltaic parks in the island of Cyprus. Energy Policy 2009;37:3673-80.

[20] Celik AN. Present status of photovoltaic energy in Turkey and life cycle technoeconomic analysis of a grid-connected photovoltaic-house. Renew Sust Energy Rev 2006;10:370-87.

[21] Celik AN, Muneer T, Clarke P. A review of installed solar photovoltaic and thermal collector capacities in relation to solar potential for the EU-15. Renew Energy 2009;34:849-56.

[22] Zahedi A. Development of an economical model to determine an appropriate feed-in tariff for grid-connected solar PV electricity in all states of Australia. Renew Sust Energy Rev 2008;13:871-8.
[23] Rigter J. Cost and optimal feed-in-tariff for small scale photovoltaic systems in China. Energy Policy 2010;38:6989-7000.

[24] Danchev S, Maniatis G, Tsakanifas A. Returns on investment in electricity producing photovoltaic systems under de-escalating feed-in-tariffs: the case of Greece. Renew Sust Energy Rev 2009;14:500-5.

[25] Papadopoulos AM, Karteris MM. An assessment of the Greek incentives scheme for photovoltaics. Energy Policy 2009;37:1945-52.

[26] Campoccia A, Dusonchet L, Telaretti E, Zizzo G. Comparative analysis of different supporting measures for the production of electrical energy by solar PV and wind systems: four representative European cases. Solar Energy 2009;83:287-97.

[27] Dusonchet L, Telaretti E. Economic analysis of different supporting policies for the production of electrical energy by solar photovoltaics in western European Union countries. Energy Policy 2010;38:3297-308.

[28] Dusonchet L, Telaretti E. Economic analysis of different supporting policies for the production of electrical energy by solar photovoltaics in eastern European Union countries. Energy Policy 2010;38:4011-20.

[29] Sivaraman D, Horne RE. Regulatory potential for increasing small scale grid connected photovoltaic (PV) deployment in Australia. Energy Policy 2011;39:586-95.

[30] Dinçer F. The analysis on photovoltaic electricity generation status. Potential and policies of the leading countries in solar energy. Renew Sust Energy Rev 2011:15:713-20.

[31] Myers KS, Klein SA, Reindl DT. Assessment of high penetration of solar photovoltaics in Wisconsis. Energy Policy 2010;38:7338-45.

[32] Widén J, Wäckelgard E, Lund PD. Options for improving the load matching capability of distributed photovoltaics: methodology and application to highlatitude data. Solar Energy 2009;83:1953-66.

[33] Paatero JV, Lund PD. Effects of large-scale photovoltaic power integration on electricity distribution networks. Renew Energy 2007;32:216-34.

[34] Denholm P, Margolis RM. Evaluating the limits of solar photovoltaics (PV) in traditional electric power systems. Energy Policy 2007;35:2852-61.

[35] Stodola N, Modi V. Penetration of solar power without storage. Energy Policy 2009;37:4730-6.

[36] Cellura M, Di Gangi A, Longo S, Orioli A. Photovoltaic electricity scenario analysis in urban contexts: an Italian case study. Renew Sust Energy Rev 2012;16:2041-52.

[37] PVsyst. Software for photovoltaic systems. University of Geneva ISE - Group Energy. FOREL Battelle. bât. D7. route de Drize CH-1227 Carouge Switzerland; 2010.

[38] Duffie JA, Beckman WA. Solar engineering of thermal processes. Wiley; 2006. p. 928.

[39] Buresch M. Photovoltaic energy systems. McGraw-Hill Book Company; 1983.

[40] Mondol JD, Yohanis YG, Norton B. The impact of array inclination and orientation on the performance of a grid-connected photovoltaic system. Renew Energy 2007;32:118-40.

[41] Dati Statistici sull'energia elettrica in Italia. Terna S.p.A. <http://www.terna.it/ default/Home/SISTEMA_ELETTRICO/statistiche/dati_statistici.aspx>.

[42] Dati statistici ISTAT: Popolazione residente - Censimento 2001 - Superficie delle abitazioni occupate da persone residenti. ISTAT. Italian National Institute of Statistics. dawinci.istat.it/MD/dawinciMD.jsp.

[43] Orioli A, Di Gangi A. Load mismatch of grid-connected photovoltaic systems: review of the effects and analysis in an urban context. Renew Sust Energy Rev 2013:21:13-28.

[44] Short W, Packey DJ, Holt TA. Manual for the economic evaluation of energy efficiency and renewable energy technologies. Golden, Colorado, US: National Renewable Energy Laboratory; 1995.

[45] Hachem C, Athienitis A, Fazio P. Parametric investigation of geometric form effects on solar potential of housing units. Solar Energy 2011;85:1864-77.

[46] Green MA, Emery K, Hishikawa Y, Warta W. Solar cell efficiency tables (version 37). Prog Photovolt: Res Appl 2011;19:84-92. 